\title{
2 Die Ebene der Geschichte
}

\subsection{Die Elemente der Handlung}

Im ersten Kapitel war bereits die Rede von den Ebenen des Erzähltextes, die im russischen Formalismus durch die Unterscheidung zwischen fabula und sjužet konzipiert und im französischen Strukturalismus durch die Begriffe Geschichte (histoire) und Diskurs (discours) modifiziert wurden, aber bereits antike Vorläufer aufweisen (s. Kap. 1.2). Hierbei handelt es sich um ein Modell der narrativen Konstitution, das in der modernen Erzähltheorie noch weiter ausdifferenziert wurde. ${ }^{168}$ Auch für eine derartige Ausdifferenzierung hat es bereits antike Ansätze gegeben.

Als Beispiele für die modernen Modelle der narrativen Konstitution seien erwähnt die Unterscheidung zwischen Ereignis, Geschehen und Geschichte, die Martínez und Scheffel konzipieren, und Schmids Differenzierung zwischen Geschehen, Geschichte, Erzählung und Präsentation der Erzählung. Den Begriff „Ereignis“ (oder „Motiv“) definieren Martínez und Scheffel als elementare Einheit eines narrativen Textes im Bereich der Handlung. Unter einem Geschehen verstehen sie die chronologische Verknüpfung von Ereignissen (erst geschieht A, dann B), wohingegen die Geschichte als kausale Verknüpfung von Ereignissen definiert wird (weil A geschehen ist, geschieht B). ${ }^{169}$

Schmid versteht unter einem Geschehen die amorphe Gesamtheit der Situationen, Figuren und Handlungen, die im Erzählwerk explizit dargestellt oder logisch impliziert sind. Das Geschehen will er somit i. S.v. Šklovskijs formalistischem Fabelbegriff verstanden wissen, ${ }^{170}$ wobei es aber nicht als ästhetisch indifferentes Material, sondern als bereits ästhetisch relevantes Resultat der Erfindung zu be-

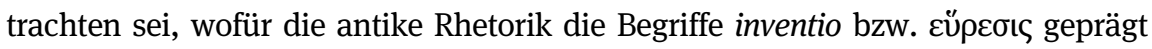
habe. Die Geschichte definiert er als Resultat einer Auswahl aus dem Geschehen, bei der bestimmte Geschehensmomente (Situationen, Figuren und Handlungen) mit einer bestimmten Qualität ausgewählt werden, und das heißt: explizit dargestellt und nicht impliziert werden. Somit will er diesen Begriff verstanden wissen i. S.v. Tomaševskijs Fabelbegriff und Todorovs Begriff der histoire (s. Kap. 1.2). In der Terminologie der antiken Rhetorik sei die Geschichte das Resultat der Disposi-

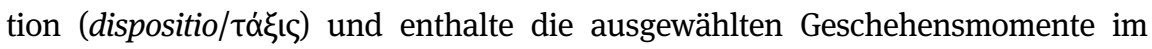
ordo naturalis. Unter der Erzählung versteht Schmid das Resultat der Komposition, die die Geschehensmomente in einen ordo artificialis überführt. Die Präsentation

168 Vgl. Schmid (2014, 205-250).

169 Vgl. Martinez und Scheffel (2016, 27 und 115).

170 Vgl. Šklovskij (2009 [1921], 34). 
der Erzählung schließlich ist als Phäno-Ebene die einzige Ebene, die der empirischen Beobachtung zugänglich ist, da die Erzählung in einem Medium dargestellt wird. In der Terminologie der antiken Rhetorik sei sie das Resultat der elocutio/ $\lambda \dot{\xi} \xi ı{ }^{171}$

Gerade mit Blick auf Schmids Differenzierung zwischen Geschehen, Geschichte, Erzählung und Präsentation der Erzählung ist augenscheinlich, dass sie Korrespondenzen in der antiken Rhetorik aufweist. Allerdings sind nicht alle Ent-

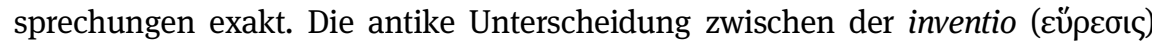
und der elocutio ( $\lambda \varepsilon \dot{\xi} \zeta \varsigma$ ) kann - in einem weiteren Sinn - als ein Vorgänger der Unterscheidung zwischen den beiden Ebenen des Erzähltextes, der Geschichte und der Darstellung, angesehen werden (s. Kap. 1.2.1). Für die inventio, das Finden und teilweise auch das Erfinden des Stoffes, ist aber nicht ein bereits ästhetisch relevantes Material konstitutiv. Vielmehr muss der Stoff relevant für den Fall sein, der verhandelt wird, selbst wenn es sich um einen vollkommen unbedeutenden Fall handelt, und dem Ziel dienen, den eigenen Standpunkt möglichst überzeugend dastehen zu lassen. ${ }^{172}$ In der Regel ist der Stoff chronologisch geordnet, da die chronologische Reihenfolge der Ereignisse zur Forderung nach Deutlichkeit gehört, die insbesondere für die Erzählung (narratio), aber nicht nur für diesen Teil der Rede gilt. ${ }^{173}$ Daher ist der ordo naturalis nicht erst das Produkt der

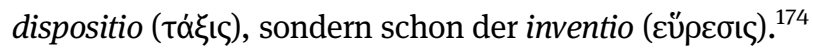

Bei der dispositio ( $\tau \alpha \dot{\xi} \xi \varsigma$ ) handelt es sich um die Stoffgliederung. Sie ist definiert als geordnete Einteilung der gefundenen und erfundenen Dinge. ${ }^{175}$ Hiermit ist nicht gemeint, dass die Ereignisse, von denen der Redner berichten wird, chronologisch geordnet sind, sondern dass der gefundene Stoff den Redeteilen

171 Vgl. Schmid (2014, 223-225).

172 Vgl. Cic. inv. 1,9: inventio est excogitatio rerum verarum aut veri similium, quae causam probabilem reddant. [Die inventio ist das Ausdenken von Dingen, die wahr oder wahrscheinlich sind und den Fall überzeugend machen.] Zur inventio vgl. Kienpointner (1998); Martin (1974, 13-210).

173 S. S. 6 f., Fn. 21. Zur chronologischen Reihenfolge der Ereignisse s. Kap. 3.1.1.

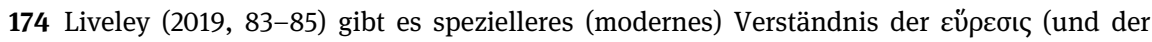
$\tau \alpha \dot{\xi} \xi \varsigma$ bzw. oíkovouía) zu erkennen, wenn sie hierin die mit dem modernen fabula-Begriff vergleichbare, aber bereits vorgeformte (mythische) Geschichte (und in der oikovo $\mu$ í $\alpha$ ihre Anordnung im Sinn des discours) erblickt. Zur oikovouía (oeconomia) s. S. 62 und Kap. 3.1.1.

$175 \mathrm{Vgl}$. Cic. inv. 1,9: dispositio est rerum inventarum in ordinem distributio [Die dispositio ist die Einteilung der gefundenen Dinge in eine Ordnung.]; rhet. Her. 1,3: dispositio est ordo et distributio rerum, quae demonstrat, quid quibus locis sit conlocandum. [Die dispositio ist die Ordnung und Einteilung der Dinge, die zeigt, was an welchen Stellen platziert werden muss.] $\mathrm{Zu}$ den wenigen Instruktionen zur dispositio vgl. rhet. Her. 3,16-18; Calboli Montefusco (1994); Martin (1974, 211-243). 
(partes orationis) zugeordnet wird: der Einleitung, Erzählung, Beweisführung etc. Es gibt zwar auch bei der dispositio ( $\tau \alpha \dot{\xi} ı \varsigma)$ eine Unterscheidung zwischen einer sozusagen natürlichen (ordo naturalis) und einer artifiziellen Reihenfolge (ordo artificiosus). Aber auch diese betrifft die Redeteile: Der Redner kann sich entweder schulbuchmäßig an die konventionelle Reihenfolge halten oder von dieser abweichen. ${ }^{176}$ Ein ordo artificialis in Sinne einer Abweichung von der chronologischen Reihenfolge der Ereignisse bei der Erzählung ist die Ausnahme von der Regel, die

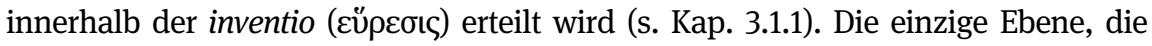
der empirischen Beobachtung zugänglich ist, ist in der antiken Rhetorik die Rede (oratio) als Produkt aller fünf Arbeitsstadien des Redners (officia oratoris), das nicht nur vorbereitet, sondern auch vorgetragen und überliefert wurde.

Einen näheren Bezug zu den Elementen der Handlung, die in der modernen Erzähltheorie diskutiert werden, weisen einerseits andere in der Rhetorik unterschiedene Elemente der Erzählung auf. Andererseits sind Aristoteles' Unterscheidung der qualitativen Teile der Tragödie und viele weitere seiner Beobachtungen insbesondere zur Handlung wichtige Vorläufer der modernen Elemente der Handlung bzw. der Modelle der narrativen Konstitution.

Im Folgenden wird systematisch zwischen zwei verschiedenen Arten von Elementen der Erzählung unterschieden, da die eine Distinktion analytisch die kleinsten Bestandteile nennt, die innerhalb einer Erzählung unterschieden werden können (Kap. 2.1.2). Andere antike Überlegungen behandeln sozusagen aus synthetisch-kompositorischer Perspektive die Frage, wie sich die Ereignisse $\mathrm{zu}$ einer (einheitlichen) Handlung zusammenfügen und mit den anderen Elementen der Erzählung interagieren. Hierzu gehören die antiken Reflexionen über die Motivierung und Plausibilität der Erzählung, die insbesondere für die Differenzierung zwischen Geschehen und Geschichte, die Martínez und Scheffel treffen, relevant sind, aber auch insgesamt die Überlegungen über die Ange-

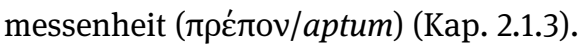

Zuerst wird aber die Auswahl der Ereignisse behandelt (Kap. 2.1.1), da auch hierüber in der antiken Erzähltheorie reflektiert wurde, wenngleich sich diese

176 Vgl. rhet. Her. 3,17: est autem alia dispositio, quae, cum ab ordine artificioso recedendum est, oratoris iudicio ad tempus adcommodatur; ut si ab narratione dicere incipiamus aut ab aliqua firmissima argumentatione aut litterarum aliquarum recitatione. [Es gibt auch eine andere Stoffgliederung, die, wenn man von der artifiziellen Ordnung abweichen muss, durch das Urteilsvermögen des Redners dem Umstand angepasst wird; z. B. wenn wir mit der Erzählung die Rede beginnen oder mit einer sehr starken Argumentation oder dem Referat irgendeines Schriftstückes.] Zu diesen Schriftstücken gehört zum Beispiel ein Gesetz; vgl. Cic. inv. 1,21. Zur Opposition zwischen dem ordo naturalis und dem ordo artificiosus vgl. auch Sulpicius Victor 14 (RhLM 320,11-29 Halm). Zum Ausdruck ordo artificialis s. Kap. 3.1. 
Reflexionen zumeist nicht an derselben Stelle finden, an der die Elemente der Erzählung (im Sinn der ausgewählten Ereignisse) besprochen werden. ${ }^{177}$

\subsubsection{Die Auswahl der Ereignisse}

In der antiken Erzähltheorie finden sich Überlegungen zur Auswahl der Ereignisse, ohne dass ein eigener Fachbegriff hierfür geprägt wurde. ${ }^{178}$ Über die Auswahl der Ereignisse reflektiert z. B. Aristoteles im achten Kapitel der Poetik. Dort lehrt er, dass eine einheitliche Handlung nicht daraus resultiert, dass der Dichter beliebige Ereignisse zusammenstellt, die eine Person getan hat oder die ihr widerfahren sind, da eine beliebige Auswahl aus den Ereignissen keine Einheitlichkeit garantiert: ${ }^{179}$

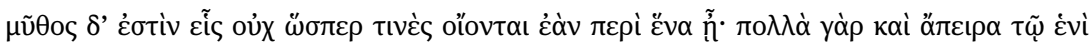

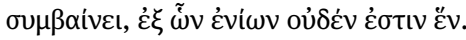

[Eine Handlung ist nicht dann einheitlich, wie manche meinen, wenn sie von einem Menschen handelt. Denn einem Menschen geschieht unzählig vieles, aus dem eine beliebige Auswahl keine Einheit ist.]

Als Negativbeispiel nennt Aristoteles dichterische Darstellungen von Herakles oder Theseus, in denen beliebige Taten und Geschehnisse behandelt werden, die die Helden getan haben oder die ihnen widerfahren sind. Als Vorbild wird Homer erwähnt, der die Odyssee nicht in der Form konzipiert hat, dass er (fast)

177 Die Auswahl der Ereignisse ist für die moderne Erzähl- und Fiktionstheorie auch insofern zentral, als in ihr eine Operation gesehen wurde, durch die historische Fakten fiktionalisiert werden. Hierfür können die Überlegungen des Geschichtsphilosophen Hayden White als repräsentativ angesehen werden; vgl. White (1978), die dt. Übersetzung White (1986) und White (1991 [1973]). Aus literaturwissenschaftlicher Sicht ist Whites Gleichsetzung von Narration, Literarität und Fiktionalität allerdings fragwürdig - nicht zuletzt deswegen, weil alles als fiktionale Darstellung angesehen werden müsste (Panfiktionalität); vgl. Zipfel (2001, 171-179); Nünning (1999); Feddern (2018, 68-74). Zum Problem der Panfiktionalität (auch Panfiktionalismus genannt) vgl. Konrad (2014). Zur Einordnung von Whites Theorie in den geschichtsphilosophischen Diskurs der zweiten Hälfte des zwanzigsten Jahrhunderts vgl. Scholz Williams (1989).

178 Vgl. außer den im Folgenden zitierten Stellen das von Servius in seinem Aeneis-Kommentar als poetisches Prinzip bezeichnete non omnia exprimere [nicht alles auszudrücken] im Zusammenhang damit, dass Vergil nicht jeden Anbruch eines Tages oder einer Nacht wiedergibt; vgl. Serv. Aen. 1,223; Lazzarini (1989, 94f.); Cyron (2009, 130 f.). Zum spätantiken Vergil-Kommentator Servius s. Kap. 3.1.1.

179 Arist. Poet. 1451a16-18 mit einer Übersetzung teilweise nach Schmitt (2011, 13). Ein Substantiv i. S.v. „Auswahl“ benutzt Aristoteles nicht. Stattdessen verwendet er den Neutrum Plural हैvia [einige]. 
alles dargestellt hat, was Odysseus zugestoßen ist. Denn seine Verwundung auf dem Parnass und das Vortäuschen von Wahnsinn bei der Heeresversammlung haben nichts mit der Handlung der Odyssee zu tun. ${ }^{180}$

Auch in den Überlegungen über die Technik, in medias res zu gehen, sind Reflexionen über die Auswahl des Stoffes zu erkennen. Man könnte meinen, dass dieser Ausdruck bedeutet, dass die chronologische Reihenfolge der Ereignisse signifikant verändert wird und vorher passierte Ereignisse später erzählt werden (zu Anachronien s. Kap. 3.1.1). Dieser Aspekt ist aber allenfalls sekundär. Vielmehr ist mit in medias res gemeint, dass ein Autor seinen Stoff so wählt, dass er nicht $a b$ ovo den gesamten Mythos erzählt, sondern sich aus inhaltlich-ästhetischen Gründen auf einen Ausschnitt beschränkt. In diesem Sinn ist Horaz' anerkennende Äußerung über Homer zu verstehen: ${ }^{181}$

\begin{abstract}
nec reditum Diomedis ab interitu Meleagri, nec gemino bellum Troianum orditur ab ovo; semper ad eventum festinat et in medias res non secus ac notas auditorem rapit, et quae desperat tractata nitescere posse relinquit.
\end{abstract}

[Er beginnt nicht die Rückkehr des Diomedes mit dem Tod des Meleager oder den Trojanischen Krieg mit dem Zwillingsei; er eilt immer zum Ende und reißt den Zuhörer mitten in die Handlung hinein, nicht anders, als wenn diese bekannt wäre, und er lässt dasjenige aus, dessen Behandlung ihm keinen Glanz verspricht.]

Anders als bei den Negativbeispielen, die in den ersten beiden Versen genannt werden, ${ }^{182}$ setzt die Handlung der Ilias und der Odyssee jeweils am Ende des Mythos ein. Um das Beispiel der Ilias zu wählen: In ihr wird nicht der ganze Krieg der Griechen gegen die Trojaner inklusive der Vorgeschichte ausführlich erzählt, sondern die Handlung setzt im zehnten Jahr der Belagerung ein und konzentriert sich auf einen kurzen Ausschnitt (51 Tage Handlung werden mehr

180 Vgl. Arist. Poet. 1451a18-35; s. teilweise Kap. 2.1.3.1.

181 Hor. ars 146-150. Zu in medias res vgl. Meijering (1987, 146-148). Zur Ars poetica allgemein vgl. die Kommentare von Brink (1971), Kiessling und Heinze (1959) und Fedeli (1997); Ferenczi und Hardie (2014); Glinatsis (2013); Reinhardt (2013); Laird (2007); Russell (2006).

182 Welcher Autor eine Erzählung über die Rückkehr des Diomedes verfasst hat und sie mit dem Tod des Großonkels Meleager beginnt, ist ebenso unsicher wie die Frage, woher (Troja oder Theben) Diomedes zurückgekehrt ist. Möglicherweise handelt es sich um Antimachos, den die antiken Kommentatoren nennen; vgl. Brink (1971, 220). Im zweiten Beispiel (V. 147) ist die Geburt von Helena gemeint, die zusammen mit ihren Brüdern Castor und Pollux aus einem Ei entsprungen ist. In jedem Fall will Horaz sagen, dass Homer nicht lang und breit die irrelevante Vorgeschichte des Trojanischen Krieges bzw. der Irrfahrten des Odysseus schildert, sondern einen geeigneten Ausschnitt wählt. 
oder minder ausführlich geschildert: 15 Tage und 5 Nächte sind erzählte Handlung, der Rest ist nur benannte Zeit). ${ }^{183}$ Da die antiken Rezipienten mit dem Mythos vertraut waren, stellte es kein nennenswertes Verständnisproblem dar, dass Homer die Handlung nach dem Proömium mit dem Streit zwischen Achill und Agamemnon beginnen lässt.

Der Ausdruck in medias res bezeichnet daher die Auswahl eines spannenden Stoffes, die sich zusätzlich dadurch auszeichnet, dass die Handlung unvermittelt einsetzt und einleitende Informationen ausbleiben, da sie als bekannt vorausgesetzt werden. Vorher stattgefundene Ereignisse können später in Form einer Analepse erzählt werden, sie müssen aber nicht nachgetragen werden.

Dieselbe Vorstellung über die Auswahl des Stoffes findet sich auch in PseudoPlutarchs Essay über Homer (De Homero) im Zusammenhang mit Reflexionen über die zweckmäßige Anordnung (oikovouí $\alpha$ ) der Ereignisse. Dort äußert der Autor aber zusätzlich Beobachtungen zum Nachtragen der vorher unerwähnten Ereignisse: ${ }^{184}$

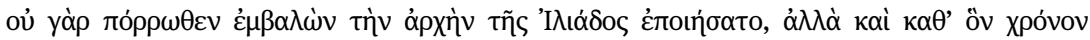

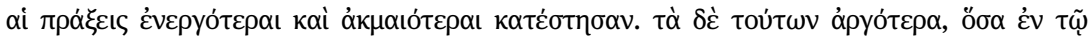

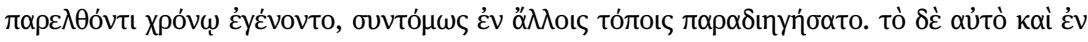

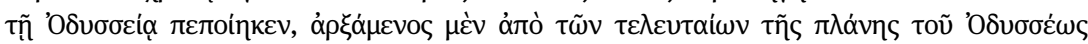

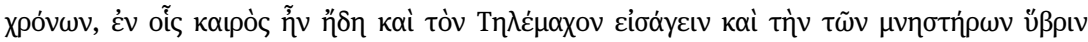

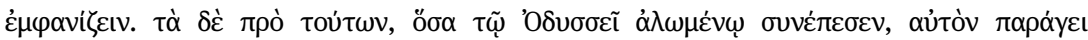

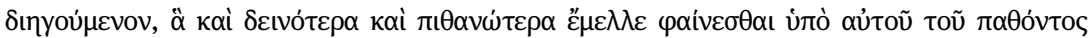
$\lambda \varepsilon \gamma o ́ \mu \varepsilon v \alpha$.

[Er hat nämlich den Anfang der Ilias nicht gedichtet, indem er weit zurückgriff, sondern mit Blick auf diejenige Zeit, zu der die Handlungen anschaulicher und reicher an Höhepunkten waren. Die weniger ereignisreichen Teile, die in der vorigen Zeit geschehen waren, hat er kurz an anderen Stellen in einer Nebenerzählung erwähnt. Dasselbe hat er auch in der Odyssee gemacht, indem er am Ende der Irrfahrt des Odysseus angefangen hat, an dem sich schon die Gelegenheit ergab, Telemachos einzuführen und den Hochmut der Freier darzustellen. Das Vorige, was dem umherirrenden Odysseus zugestoßen ist, lässt er ihn selbst erzählen, weil er wollte, dass es eindringlicher und plausibler erscheint, wenn es von demjenigen gesagt wird, der es selbst erlitten hat.]

Homer hat also diejenigen Ereignisse herausgegriffen, die anschaulicher und reicher an Höhepunkten waren, indem er die Handlung der Ilias im zehnten Kriegsjahr und diejenige der Odyssee mit (Odysseus' Aufenthalt bei Kalypso und) der Schilderung der Zustände auf Ithaka beginnen lässt. ${ }^{185}$ Die vorher

183 Vgl. Latacz $(1985,151)$.

184 Ps.Plut. Hom. 162. Vgl. zu dieser Stelle den Kommentar von Hillgruber (1999, 349-351).

185 Im ersten Buch der Odyssee wird nach dem Proömium (V. 1-10) zunächst Odysseus' Aufenthalt bei Kalypso geschildert (V. 11-21). Dann folgt eine Götterversammlung (V. 22-95), die dazu 
stattgefundenen Ereignisse lässt Homer aber nicht unerwähnt, sondern trägt sie in Analepsen nach (zu Anachronien s. Kap. 3.1.1). Im Fall der Odyssee besteht die entsprechende Analepse darin, dass Odysseus seine phantastischen Abenteuer in den Büchern 9 bis 12 der Odyssee den Phäaken erzählt. Der Mehrwert dieser Analepse liegt Pseudo-Plutarch zufolge darin, dass Odysseus' Schilderung seiner phantastischen Irrfahrten in eigener Person plausibler ist und stärker wirkt, als wenn der Autor sie erzählen würde.

Auch für die historiographische Darstellung sind die Auswahl der Ereignisse und das Kriterium der Relevanz und Einheitlichkeit wichtig, und zwar nicht in der Form, dass in der annalistischen Geschichtsschreibung alle Ereignisse in einem kohärenten Zusammenhang dargestellt werden (zur Motivierung der Ereignisse in der Geschichtsschreibung s. Kap. 2.1.3.3), sondern in der Form, dass bei der Schilderung der Einzelereignisse die relevanten Taten und Reden dargestellt werden müssen. Derartige Reflexionen finden sich u. a. in Polybios’ Timaios-Polemik an einer Stelle, an der Polybios die Reden seines Vorgängers kritisiert: ${ }^{186}$

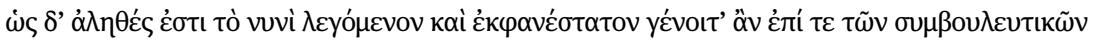

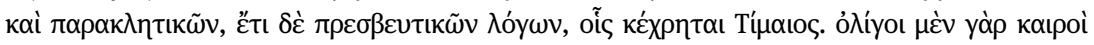

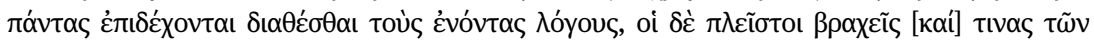

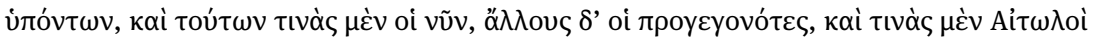

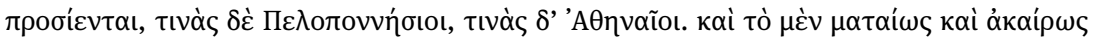

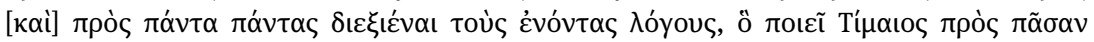
ن்

[Dass das gerade Gesagte [sc. die Beschäftigung mit schriftlichen Quellen sei wichtig] richtig ist, ist besonders deutlich bei den Beratungsreden, Feldherrenreden und ferner den Gesandtschaftsreden, die Timaios verwendet hat. Denn nur wenige Gelegenheiten lassen es $\mathrm{zu}$, alle relevanten Reden darzustellen; die meisten [sc. Gelegenheiten] lassen einige kurze Reden der Anwesenden zu, und von diesen lassen die jetzt Lebenden die einen zu, die Vorfahren andere, und die Aitoler lassen die einen zu, die Peloponnesier andere und die Athener wieder andere. Wahllos bei jeder Gelegenheit alle relevanten Reden detailliert zu berichten, was Timaios zu jedem Thema einfallsreich macht, entspricht überhaupt nicht der Wahrheit [. . .].]

führt, dass sich Athene nach Ithaka begibt, wo sie mit Telemachos, dem Sohn des Odysseus, über die Zustände am Hof, v. a. das dreiste Verhalten der Freier, die um Penelopes Hand anhalten, spricht und ihm dazu rät, eine Volksversammlung einzuberufen und anschließend in Pylos und Sparta Informationen über seinen Vater einzuholen (V. 96-323). Die Verwirklichung dieser Pläne steht im Mittelpunkt der ersten vier Bücher der Odyssee, der sog. Telemachie.

186 Polyb. 12,25i2-5. Zu Polybios' Timaios-Polemik s. auch Kap. 2.1.3.3 und vgl. Fögen (1999); Feddern (2018, 155-157). 
Polybios geht von der unausgesprochenen Prämisse aus, dass die Figurenreden der Historiker nicht die ursprünglich gehaltenen Reden wörtlich wiedergeben, sondern mehr oder weniger realistische Fiktionen sind (zur Redenfiktion s. Kap. 1.4.2.1). Ihm zufolge begeht Timaios aufgrund fehlender Sachkenntnisse den Fehler der Ausführlichkeit, indem er zu viele zu lange Reden schildert, da in Wirklichkeit nicht so viele so lange Reden gehalten sein können. Er hätte sie vielmehr kürzen und an die Personen und Umstände anpassen müssen. Von denjenigen Reden, die Timaios fingiert hat, sind nach Polybios viel weniger Reden relevant, als es sein Vorgänger eingeschätzt hat. In ähnlicher Form erhebt Polybios gegen Büchergelehrte wie Timaios den Vorwurf, dass sie irrelevante (topographische) Informationen geben und relevante auslassen, ${ }^{187}$ und wirft Phylarchos vor, bei der Darstellung des Kleomenischen Krieges zwar das Unglück der Mantineer in einer ausschmückenden Darstellung erzählt zu haben, über den Großmut der Megalopoliten aber, den sie zu derselben Zeit bewiesen hätten, nicht das geringste Wort verloren $\mathrm{zu}$ haben. ${ }^{188}$

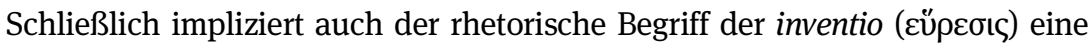
Auswahl aus den Ereignissen, und zwar derjenigen Ereignisse, die für den verhandelten Fall relevant sind und dem Ziel dienen, den eigenen Standpunkt möglichst überzeugend dastehen zu lassen. Explizit gemacht wird dieser Auswahlprozess im Zusammenhang mit der Erzählung (narratio), die einen fakultativen Teil der Rede darstellt, da sie zumeist auf die Einleitung folgt, aber nicht immer folgen muss. Bei der Aussparung von Ereignissen oder sogar der gesamten Erzählung muss man zwischen mehreren Möglichkeiten unterscheiden. ${ }^{189}$ Insgesamt gesehen soll der Redner dasjenige, was gegen ihn spricht, übergehen, soweit es übergangen werden kann, oder es nur tangieren, wenn es nicht übergangen werden kann, und seine eigenen Punkte gründlich und deutlich vorbringen. ${ }^{190}$

187 Vgl. Polyb. 12,25g3f.

188 Vgl. Polyb. 2,61,1-3. Zu Polybios' Polemik gegen Phylarchos s. Kap. 3.2.1.3.

189 Wenn sie dem eigenen Ziel schaden würde, muss man Einzelheiten der Erzählung im Laufe der Rede (Argumentation) nachtragen und sofort im Sinn des eigenen Beweiszieles ausdeuten. Die Erzählung muss gänzlich ausgelassen werden, wenn die Gegenseite bereits den Tathergang geschildert hat und es sinnlos wäre, denselben Sachverhalt wiederum, also ohne signifikante Änderung, zu schildern. In beiden Fällen werden die Ereignisse, die nicht (in einer zusammenhängenden Erzählung) erzählt werden, als wirklich aufgefasst.

190 Vgl. Cic. inv. 1,30. 


\subsubsection{Die Bestandteile der Erzählung}

\subsubsection{Die qualitativen Teile der Tragödie nach Aristoteles}

Aristoteles unterscheidet im sechsten Kapitel seiner Poetik zwischen sechs qualitativen Teilen der Tragödie und schätzt ihre Bedeutung folgendermaßen

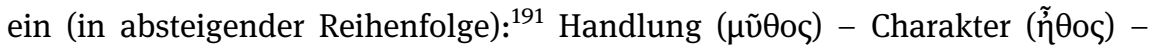

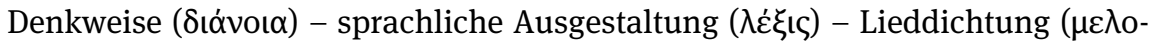
$\pi$ oı́ $\alpha$ ) - Aufführung (ő $\psi \varsigma$ ). Analog sind diese qualitativen Teile der Tragödie in der genannten absteigenden Reihenfolge mehr oder minder relevant auch für die anderen erzählenden Gattungen und für die moderne Erzähltheorie. Daher sollen insbesondere die Handlung und die Charaktere kurz beleuchtet werden, da sie - in modifizierter Form - auch in der modernen Unterscheidung zwischen der Handlung und den Handlungsträgern zum Vorschein kommen, während die anderen qualitativen Teile eher spezifische Geltung für die inszenierte Tragödie besitzen. ${ }^{192}$

Die Handlung, der Aristoteles den Vorrang vor allen anderen Komponenten der dichterischen Produktion gibt, ${ }^{193}$ versteht er als Verknüpfung der Ereignisse

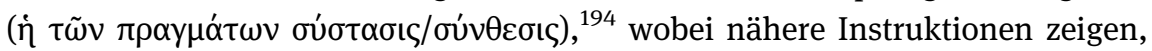
dass er damit die einheitliche Handlung und die plausible Verknüpfung der Ereignisse, ihre Motivierung, meint (s. Kap. 2.1.3.1). Aristoteles unterscheidet zwar nicht durch zwei verschiedene Substantive zwischen der kausal motivierten und der chronologischen Abfolge der Ereignisse. Er trifft aber dadurch eine terminologische Unterscheidung zwischen diesen beiden Arten der Handlung,

191 Vgl. Arist. Poet. 1450a7-b20. Die quantitativen Teile der Tragödie wie Prolog, Epeisodion und Exodos unterscheidet Aristoteles in Kapitel 12 der Poetik.

192 Die Lieddichtung und die Aufführung haben spezifische Geltung für die inszenierte Tragödie, nicht aber für das Epos und andere Gattungen; vgl. Arist. Poet. 1459b9f. Zur Auffüh-

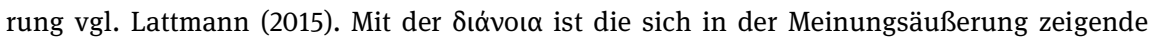
Denkweise gemeint, wie die entsprechenden Stellen in Kapitel 6 und 19 zeigen; vgl. Arist. Poet. 1450a6f.; b4-8 und 11f.; 1456a34-b2. Zu den sechs qualitativen Teilen der Tragödie vgl. Schmitt (2011, 326-332) mit den Literaturhinweisen (360f.); zur Unterscheidung zwi-

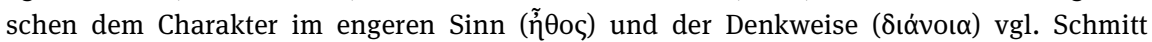
(2011, 354-360).

193 Vgl. Arist. Poet. 1450a15; 22f.; $38 \mathrm{f}$.

194 Vgl. Arist. Poet. 1450a4f. und s. die vorige Fn. Zur Handlung als Grundbegriff von Aristoteles’ Tragödientheorie vgl. Kannicht (1976). Zu Handlung und Handlungslogik bei Aristoteles und anderen antiken Autoren vgl. Baumbach (2019). 
dass er die nur chronologische Ereignissequenz im zweiten Teil des neunten Kapitels der Poetik als episodische Handlung bezeichnet: ${ }^{195}$

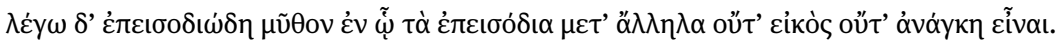

[Ich nenne eine Handlung episodisch, bei der es weder wahrscheinlich noch notwendig ist, dass die Episoden aufeinander folgen.]

Die Charaktere stellen nach Aristoteles den zweitwichtigsten Teil der Tragödie dar. Anders als bei den Handlungsträgern, die in der modernen Erzähltheorie erwähnt werden, hat Aristoteles dezidiert den Charakter der Handlungsträger im Blick. Die Charaktere bespricht Aristoteles zuerst im zweiten Kapitel der Poetik, indem er zwischen den drei Objekten der Nachahmung unterscheidet: Die nachgeahmten Menschen sind hinsichtlich ihres Charakters entweder besser als der Durchschnittsmensch oder entsprechen diesem oder sind schlechter als dieser (s. Kap. 1.1.3.2). Im vierten Kapitel lehrt er, dass sich die literarischen Gattungen nach den unterschiedlichen Charakteren der Dichter ausdifferenziert haben, indem bessere Dichter bessere Menschen und schlechtere Dichter schlechtere Menschen nachgeahmt haben. ${ }^{196}$ Spezifische Instruktionen zur Gestaltung der Charaktere erteilt Aristoteles im 15. Kapitel der Poetik (s. Kap. 2.1.4).

Was das Verhältnis zwischen der Handlung und dem Charakter betrifft, gibt Aristoteles der Handlung den Vorrang. Gleichzeitig bespricht er aber das Problem, dass sich diese beiden qualitativen Teile der Handlung kaum gänzlich voneinander trennen lassen, da i.d.R. Menschen mit einem bestimmten Charakter die Handlung ausführen. Besonders deutlich kommt dieser Umstand an der folgenden Stelle zum Vorschein, an der Aristoteles darauf hinweist, dass der Charakter immer in der Handlung enthalten ist und der Handlung somit das Primat gebührt: ${ }^{197}$

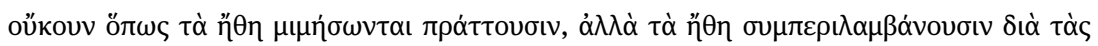
$\pi \rho \alpha \dot{\xi \varepsilon ı \zeta . ~}$

[Es ist nicht so, dass sie handeln, indem sie die Charaktere nachahmen, sondern durch die Handlungen umfassen sie auch die Charaktere.]

195 Arist. Poet. 1451b34f.

196 Vgl. Arist. Poet. 1448b24-1449a6.

197 Arist. Poet. 1450a20-22. Für das Verhältnis zwischen der Handlung und dem Charakter ist außerdem die Aristotelische Ansicht zu berücksichtigen, dass die Menschen aufgrund ihres Handelns glücklich oder unglücklich sind und dass sie aufgrund ihres Charakters die einen Dinge vorziehen und die anderen Dinge meiden; vgl. Arist. Poet. 1450a19f. und b8-11. 
Gerade auch im Zusammenhang mit der von Aristoteles geforderten Handlungslogik wird deutlich, dass die Handlung (als Zusammenfügung der einzelnen Ereignisse $\mathrm{zu}$ einer einheitlichen und kausal motivierten Handlung) der wichtigste qualitative Teil der Tragödie ist, während das Ethos ein wesentlicher Faktor ist, der zur Handlungslogik beiträgt. ${ }^{198}$

\subsubsection{Die rhetorischen Elemente der Erzählung}

In den Rhetorik- und Progymnasmata-Handbüchern werden an mehreren Stellen Elemente der erzählten Geschichte o. ä. unterschieden. In besonders ausführlicher Form passiert dies in De inventione im Zusammenhang mit der Beweisführung. Dort erfolgt zunächst eine Zweiteilung, durch die Argumente, die sich aus den Personen (personae) ergeben, von Argumenten unterschieden werden, die zu den Ereignissen (negotia) gehören. ${ }^{199}$ Dann werden elf Aspekte genannt, die die Personen betreffen, u. a. die menschliche Natur (natura) und Entschlüsse (consilia), und teilweise weiter unterteilt. Zur Natur des Menschen gehören u. a. das Geschlecht, die Herkunft, die Abstammung und das Alter. ${ }^{200}$ Dann werden die Ereignisse in vier Gruppen eingeteilt, indem unterschieden wird zwischen demjenigen, was untrennbar mit dem Ereignis verbunden ist (continentia cum ipso negotio), demjenigen, was bei der Ausführung der Tat betrachtet wird (in gestione negotii considerantur), demjenigen, was zum Vergleich herangezogen wird (adiuncta negotio), und Faktoren, die die Definition und die Qualität der Tat betreffen (consecutio). ${ }^{201}$

Untrennbar mit dem Ereignis verbunden sind u. a. die kurze und bündige Angabe, was passiert ist (z. B. die Tötung des Vaters oder der Mutter), und der Grund (causa) für die Tat. ${ }^{202}$ Bei der Ausführung der Tat werden der Ort (locus), die Zeit (tempus), die Art und Weise (modus), die Gelegenheit (occasio) und die Möglichkeit (facultas) betrachtet und weiter untergliedert. ${ }^{203} \mathrm{Zu}$ der Art und Weise (modus) gehört auch die Frage nach der Absicht (animus), ${ }^{204}$ und während die Gelegenheit als Unterbegriff der Zeit verstanden wird, ${ }^{205}$ bezeichnet die facultas die Möglichkeit in dem Sinn, dass einer Person die zur Ausführung

198 S. Kap. 1.4.1.2 (v. a. Arist. Poet. 1451b5-11); 2.1.3.1; 2.1.4; vgl. Feddern und Kablitz (2020, 52, Fn. 75).

199 Vgl. Cic. inv. $1,34$.

200 Vgl. Cic. inv. 1,34-36.

201 Vgl. Cic. inv. 1,37-43. Zur consecutio vgl. Cic. inv. 43 und teilweise Cic. de orat. 3,113.

202 Vgl. Cic. inv. 1,37.

203 Vgl. Cic. inv. 1,38-41.

204 Vgl. Cic. inv. 1,41.

205 Vgl. Cic. inv. 1,40. 
der Tat nötigen Mittel zur Verfügung standen. ${ }^{206}$ Das, was zum Vergleich herangezogen wird, kann z. B. größer oder kleiner oder ähnlich sein. ${ }^{207}$ Und zu den Faktoren, die die Definition und die Qualität der Tat betreffen, gehört neben der Definition z. B. die Frage, wer der Anstifter der Tat war. ${ }^{208}$

Die Elemente der Erzählung kommen auch bei der Unterscheidung zwischen der allgemeinen Fragestellung ( $\theta$ ćoıৎ/consultatio/propositum / quaestio [infinita])

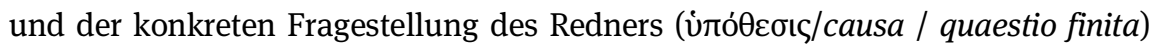
zum Tragen, die auf Hermagoras aus Temnos (zweites Jahrhundert v.Chr.) zurückgeht. Bei der Hypothese handelt es sich um einen konkreten Fall - und nur als solcher liegt er dem Redner vor -, bei dem die betreffenden Personen und

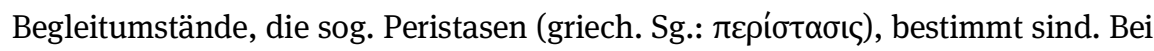
der These hingegen, die nicht das genuine Aufgabenfeld des Redners, sondern des Philosophen darstellt, die der Redner aber idealerweise auch behandelt, indem er durch Abstraktion von der konkreten Fragestellung zum allgemeinen Problem gelangt, werden die betreffenden Personen und Begleitumstände unbestimmt gelassen.

Die Hypothesen wurden mit Aristoteles anhand der genera causarum in drei

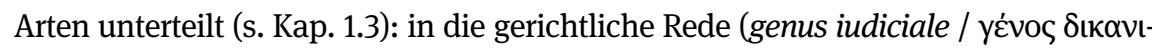

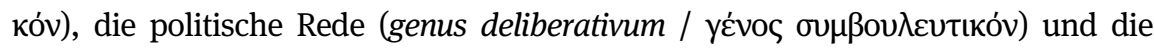

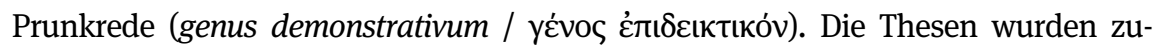
meist in theoretische und praktische Fragestellungen unterteilt. ${ }^{209} \mathrm{Zu}$ den Peristasen gehören v. a. die folgenden Elemente, die in Ciceros Topica genannt werden: ${ }^{210}$

causa certis personis, locis, temporibus, actionibus, negotiis cernitur aut in omnibus aut in plerisque eorum, propositum autem aut in aliquo eorum aut in pluribus nec tamen in maximis.

[Die Hypothese wird durch bestimmte Personen, Orte, Zeiten, Handlungen und Taten erkannt, entweder in allen [sc. Peristasen] oder in den meisten von ihnen, die These aber entweder in irgendeiner von ihnen oder in mehreren, aber dennoch nicht in den wichtigsten.]

206 Vgl. Cic. inv. 1,41.

207 Vgl. Cic. inv. 1,41f.

208 Vgl. Cic. inv. 1,43.

209 Zur Unterscheidung zwischen der allgemeinen und der konkreten Fragestellung vgl. Cic. inv. 1,8; part. 4 und 11; top. 79; Quint. inst. 3,5,5-7. Zur These vgl. Quint. inst. 2,4,24f.; Theon RhG II 120-128 Spengel (Patillon und Bolognesi 1997, 82-94); Hermog. Progym. 11 Patillon (2008, 203-205); Aphth. Progym. 13 Patillon (2008, 152-157); Nikolaos RhG XI 71-76 Felten; Priscian, Praeexercitamina Passalacqua (1987, 47 f.); Feddern (2013, 1-3 und 7-35).

210 Cic. top. 80. Ein möglicher Unterschied zwischen den Handlungen (actiones) und Taten oder Ereignissen (negotia) wird nicht erläutert; möglicherweise werden diese Begriffe mehr oder minder synonym verwendet. 


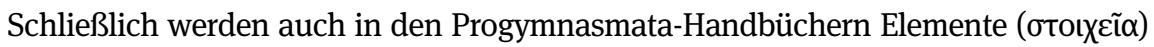
der Erzählung unterschieden. Theon unterscheidet z. B. zwischen den sechs Elementen Person(en), Ereignis, Ort, Zeit, Art und Weise und Motiv, ${ }^{211}$ wobei er diese Elemente noch weiter untergliedert. ${ }^{212}$

\subsubsection{Die Angemessenheit, Motivierung und Plausibilität der Erzählung}

In der antiken Erzähltheorie wurde über die Angemessenheit, Motivierung und Plausibilität der Erzählung nicht nur dahingehend diskutiert, wie sich die Ereignisse zu einer (einheitlichen) Handlung zusammenfügen, sondern es wurden auch Faktoren berücksichtigt, die die Kontextualisierung der Erzählung und v. a. der Figurenrede betreffen. ${ }^{213}$ In den folgenden Unterkapiteln werden derartige produktionsorientierte Vorschriften und Beschreibungen präsentiert.

\subsubsection{Aristoteles' Instruktionen zur Motivierung der dichterischen Handlung} Im Zusammenhang mit dem neunten Kapitel der Poetik war bereits die Rede

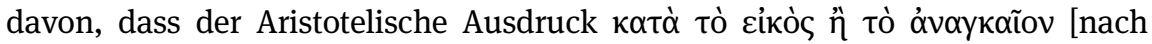
Maßgabe der Wahrscheinlichkeit oder Notwendigkeit] die Verknüpfung der Ereignisse im Sinne der Plausibilität bzw. Motivierung bezeichnet, die er zur Aufgabe des Dichters zählt (s. Kap. 1.4.1.2). Ferner zeigt schon sein Handlungsbegriff ( $\mu \tilde{v} \theta$ os), dass er die Handlung als Verknüpfung der Ereignisse versteht $(\dot{\eta} \tau \tilde{\omega} v$

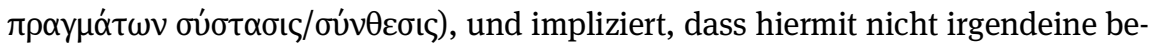
liebige Komposition gemeint ist, sondern die Zusammenstellung einer einheitlichen Handlung durch die plausible Verknüpfung der Ereignisse (s. Kap. 2.1.2.1).

Aristoteles' Instruktionen zur Verknüpfung der Ereignisse finden sich an mehreren Stellen der Poetik und stellen die wichtigsten antiken Beobachtungen zur Motivierung der Erzählung dar. ${ }^{214}$ Im siebenten Kapitel beginnt Aristoteles

211 Vgl. Theon RhG II 78,16-20 Spengel (Patillon und Bolognesi 1997, 38).

212 Vgl. Theon RhG II 78,20-79,19 Spengel (Patillon und Bolognesi 1997, $38 \mathrm{f}$.).

213 Der modernen Erzähltheorie wird mitunter vorgeworfen, Erzählungen zu schablonenhaft zu analysieren, ohne den Erzähltext vor dem Hintergrund seiner Entstehungszeit und anderer außersprachlicher oder werkimmanenter Faktoren wahrzunehmen; vgl. Nünning und Nünning (2004, 17 und 23-28) mit Blick auf erzähltheoretisch fundierte gender studies, die den Kontext der Erzählungen berücksichtigen.

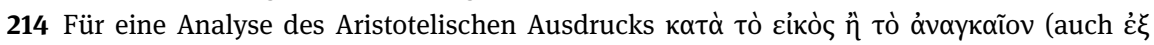

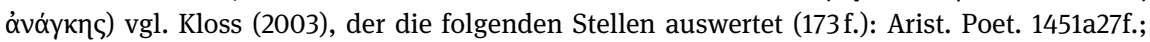
1451b34f.; 1454a33-36. Ferner verweist er auf folgende Stellen (174, Fn. 18): 1451a12f.; 1452a20 und 24; und auf folgende Stellen, an denen nur cíkós steht: 1455a7; 17; 18; b10; 1456a24; b4; 
mit einer näheren Betrachtung der Handlung, nachdem er zuvor die poetologischen Grundbegriffe eingeführt hat. Schon aus seinen einleitenden Bemerkungen wird deutlich, dass er die Handlung nicht nur als ein Nacheinander, sondern auch als ein Auseinander versteht. Denn für eine einheitliche Handlung sind ihm zufolge Anfang, Mitte und Ende konstitutiv, wobei diese drei Teile nicht nur nacheinander folgen, sondern sich auch auseinander ergeben: ${ }^{215}$

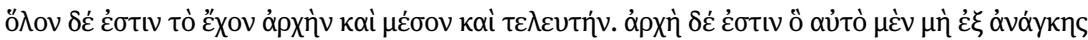

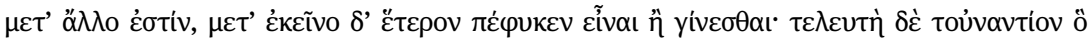

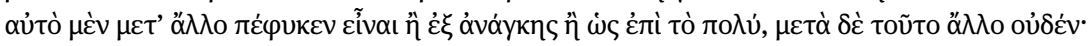

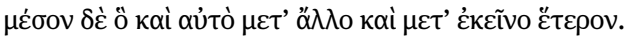

[Etwas Ganzes ist dasjenige, was Anfang, Mitte und Ende hat. Anfang ist dasjenige, was nicht notwendig nach etwas anderem ist, wonach aber natürlicherweise etwas anderes ist oder wird. Ende ist im Gegenteil, was selbst natürlicherweise nach etwas anderem ist, und zwar notwendig oder meistens, wonach aber nichts anderes ist. Mitte ist, was selbst nach etwas anderem und wonach etwas anderes ist.]

Daher darf der Dichter, wenn er seine Handlung gut zusammenstellen will, nicht an einem beliebigen Punkt anfangen und ebenso wenig aufhören (zur Auswahl der Ereignisse s. Kap. 2.1.1). Am Ende des siebenten Kapitels fasst Aristoteles seine Bemerkungen zum Umfang der Tragödie mit den folgenden Worten zusammen: ${ }^{216}$

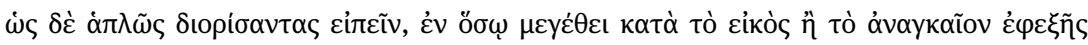

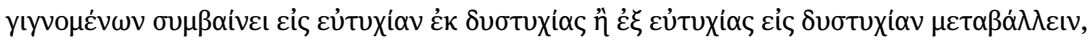

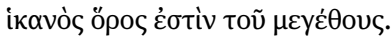

[Um eine einfache Definition zu geben: Bei welcher Art von Größe ein Umschwung vom Unglück ins Glück oder vom Glück ins Unglück erfolgt, wobei sich die Dinge nach den Regeln der Wahrscheinlichkeit oder Notwendigkeit nacheinander ergeben, ist eine ausreichende Definition der Größe.]

Im achten Kapitel äußert Aristoteles die Ansicht, dass sich eine einheitliche Handlung nicht allein dadurch konstituiert, dass all das geschildert wird, was einer Person zustößt, sondern dadurch, dass die Ereignisse kausal miteinander

1461b15. Auch in der modernen Erzähltheorie wird anerkannt, dass Aristoteles’ Äußerungen zur Motivierung der Handlung ein wichtiger Vorläufer der modernen Lehre sind; vgl. Martinez und Scheffel (2016, 123f.).

215 Arist. Poet. 1450b26-31.

216 Arist. Poet. 1451a11-15. 
verknüpft sind. Dieses Verständnis von Einheitlichkeit sieht Aristoteles bei Homer verwirklicht: ${ }^{217}$

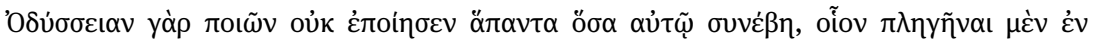

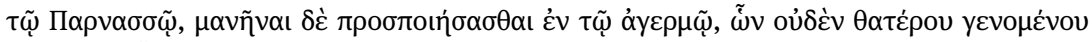

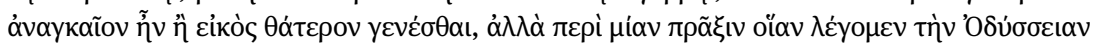

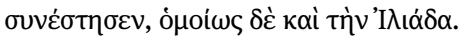

[Denn als er die Odyssee gedichtet hat, hat er nicht alles zum Gegenstand seiner Dichtung gemacht, was ihm [sc. Odysseus] widerfahren ist, wie z. B. die Verwundung auf dem Parnass, das Vortäuschen von Wahnsinn bei der Truppenaushebung - es war ja nicht notwendig oder wahrscheinlich, dass hiervon, wenn das eine geschehen ist, das andere geschieht -, sondern er hat die Odyssee auf eine Handlung, wie wir sie verstehen, angelegt und ebenso die Ilias.]

Im zehnten Kapitel definiert Aristoteles die einfachen ( $\dot{\alpha} \pi \lambda$ o ̃ $\mu \tilde{v} \theta o ı)$ und die zusammengesetzten Handlungen ( $\pi \varepsilon \pi \lambda \varepsilon \gamma \mu \varepsilon \dot{v} o \iota$ ũ̃oı). Eine zusammengesetzte Handlung weist einen Wendepunkt (Peripetie) und/oder eine Wiedererkennung (Anagnorisis) auf. $\mathrm{Zu}$ den beiden zuletzt genannten Phänomenen bemerkt Aristoteles: ${ }^{218}$

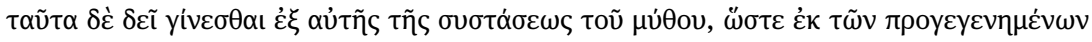

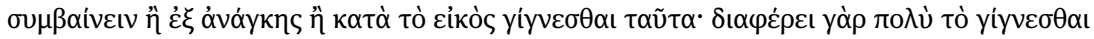

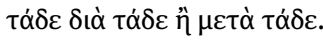

[Dies muss sich aber aus der Komposition der Handlung selbst ergeben, so dass sich dies aus dem vorher Geschehenen mit Notwendigkeit oder Wahrscheinlichkeit ergibt. Denn es ist ein großer Unterschied, ob dies deshalb oder danach geschieht.]

Aristoteles verwendet die Begriffe der Wahrscheinlichkeit und der Notwendigkeit auch in Bezug auf die Charaktere, wenn er im 15. Kapitel im vergleichenden Rückblick auf die Komposition der Handlung die analoge Forderung an die Konzeption der Charaktere stellt: ${ }^{219}$

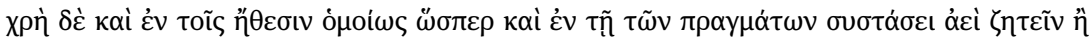

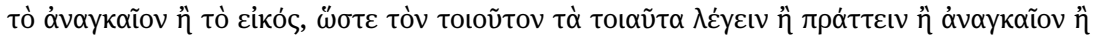

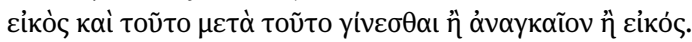

[Auch bei den Charakteren muss man ebenso wie bei der Komposition der Handlung immer das Notwendige oder das Wahrscheinliche suchen, so dass es notwendig oder wahrscheinlich ist, dass der Derartige das Derartige sagt oder tut, und notwendig oder wahrscheinlich ist, dass das eine nach dem anderen geschieht.]

217 Arist. Poet. 1451a24-30.

218 Arist. Poet. 1452a18-21.

219 Arist. Poet. 1454a33-36. 
Daher bezeichnen die Begriffe der Wahrscheinlichkeit und der Notwendigkeit in Aristoteles' Poetik zwar vorrangig, aber nicht nur die kausal motivierte Ereignisfolge, sondern beziehen sich auch auf diejenigen Personen bzw. Charaktere, die die jeweilige Handlung ausführen, und somit auf die beiden wichtigsten qualitativen Teile der Dichtung. In ähnlicher Form wie das neunte Kapitel zeigt die soeben zitierte Stelle aus dem 15. Kapitel im Verbund mit denjenigen Stellen, an denen Aristoteles die Handlung explizit als wichtigstes Bauelement der Tragödie bezeichnet, dass die Charaktere einen wichtigen Parameter darstellen, der zur Wahrscheinlichkeit oder sogar Notwendigkeit der Handlung beiträgt. ${ }^{220}$

\title{
2.1.3.2 Rhetorische Instruktionen zur Angemessenheit, Motivierung und Plausibilität der Erzählung
}

In der Herennius-Rhetorik werden im Zusammenhang mit den Instruktionen zur Erzählung (narratio) nicht nur deren Elemente erwähnt, sondern zugleich Anweisungen zur Erzeugung von Plausibilität und Angemessenheit gegeben:221

\begin{abstract}
veri similis narratio erit, si, ut mos, ut opinio, et natura postulat, dicemus; si spatia temporum, personarum dignitates, consiliorum rationes, locorum opportunitates constabunt, ne refelli possit aut temporis parum fuisse, aut causam nullam, aut locum idoneum non fuisse, aut homines ipsos facere aut pati non potuisse. si vera res erit, nihilominus haec omnia narrando conservanda sunt; nam saepe veritas, nisi haec servata sint, fidem non potest facere: sin erunt ficta, eo magis erunt conservanda.
\end{abstract}

[Die Erzählung wird plausibel sein, wenn wir so sprechen, wie es Konvention, Meinung und Natur fordern; wenn die Zeitabschnitte, die Würde der Personen, die Gründe für die Entschlüsse und die topographischen Möglichkeiten feststehen, damit etwas nicht mit dem Einwand widerlegt werden kann, dass zu wenig Zeit dazu war oder kein Grund dafür bestand oder der Ort nicht geeignet war oder die Menschen selbst es nicht hätten tun oder erleiden können. Wenn der Sachverhalt wahr ist, muss man trotzdem all das zuvor Genannte durch das Erzählen beibehalten. Denn häufig erzeugt die Wahrheit, wenn dies nicht bewahrt sein sollte, keinen Glauben. Wenn es aber erfunden ist, muss man dies umso mehr beobachten.]

Als Elemente der Erzählung lassen sich identifizieren: Zeit, Person, Motiv und Ort. Der Schwerpunkt der Instruktionen liegt aber darauf, dass diese Elemente in einem angemessenen und stimmigen Verhältnis zueinander stehen: Es muss sichergestellt werden, dass die Erzählung überzeugend wirkt, dass ein be-

220 S. Kap. 1.4.1.2 (v. a. Arist. Poet. 1451b5-11); 2.1.2.1; 2.1.4; vgl. Feddern und Kablitz (2020, 52, Fn. 75).

221 Rhet. Her. 1,16. Vgl. auch Cic. inv. 1,28f. Für die Vorstellung, dass die Realität manchmal so ungewöhnlich ist, dass sie nicht glaubhaft wirkt, vgl. Arist. Poet. 1460a26f. und 1461b11f.; Quint. inst. 4,2,34. 
stimmter Mensch einer anderen Person aus einem nachvollziehbaren Grund an einem geeigneten Ort in der dafür nötigen Zeit etwas angetan hat.

Besonders ausführliche Anweisungen zur Erzeugung von Plausibilität und Angemessenheit werden auch im Zusammenhang mit der Figurenrede (Prosopopoiie) gegeben. ${ }^{222}$ So heißt es in Theons Progymnasmata-Handbuch: ${ }^{223}$

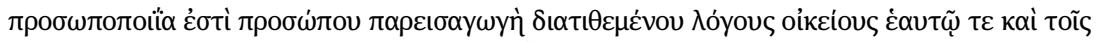

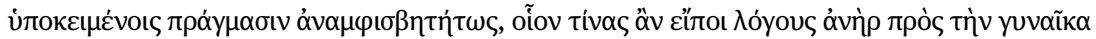

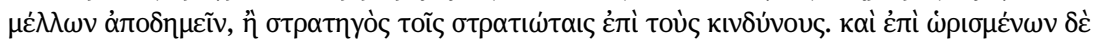

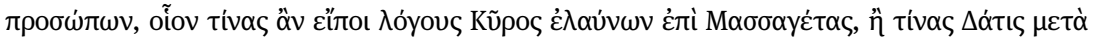

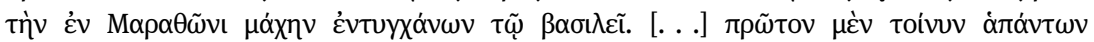

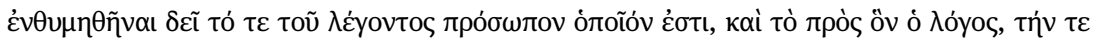

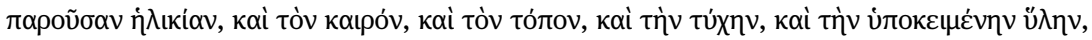

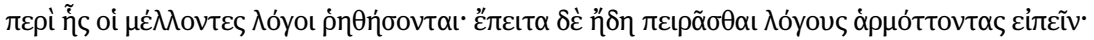

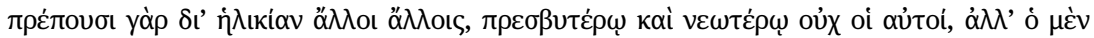

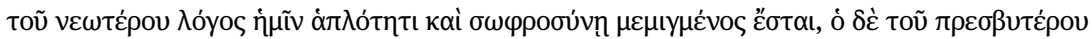

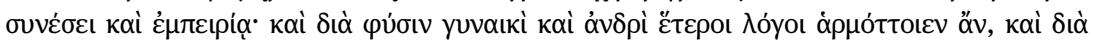

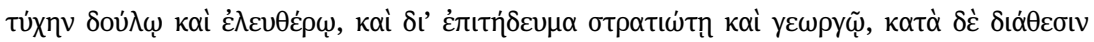

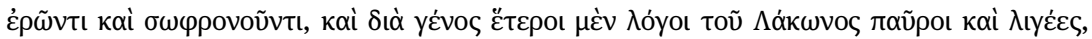

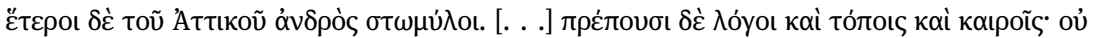

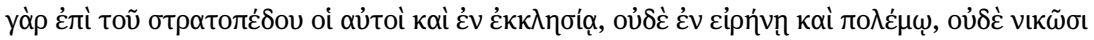

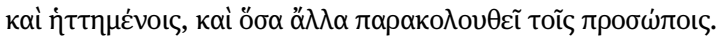

[Eine Prosopopoiie ist eine Einführung einer Person, die Worte spricht, die unzweifelhaft ihr und dem zugrunde liegenden Sachverhalt angemessen sind; z. B.: welche Worte ein Mann zu seiner Frau spricht, wenn er auf eine Reise geht, oder ein Feldherr zu den Soldaten angesichts von Gefahren. Und bei bestimmten Personen z. B., welche Worte Kyros

222 Die Prosopopoiie war sowohl die separate Schulübung der Figurenrede als auch die Figurenrede innerhalb eines Erzähltextes. Quintilian (Quint. inst. 9,2,29-37) und Theon (RhG II 115-118 Spengel; Patillon und Bolognesi 1997, 70-73) unterscheiden nicht zwischen der Prosopopoiie, der Ethopoiie und der Eidolopoiie. Andere Rhetoren unterscheiden zumindest zwischen der Prosopopoiie und der Ethopoiie, teilweise auch noch der Eidolopoiie, indem in der Prosopopoiie Dinge, in der Eidolopoiie Tote und in der Ethopoiie historische, also nach antikem Verständnis auch mythische, oder erfundene Personen reden; s. Kap. 2.1.4 und vgl. die Quint. inst. 9,2,31 referierte Gegenmeinung; Aquila RhLM 23f. Halm. Zum Progymnasma der Prosopopoiie vgl. auch Suet. gramm. 4,5; Nikolaos RhG XI 63-67 Felten; Priscian, Praeexercitamina Passalacqua (1987, 45f.).

223 Theon RhG II $115 \mathrm{f}$. Spengel (Patillon und Bolognesi 1997, 70f.); vgl. auch die englische Übersetzung von Kennedy (2003, 47 f.). Zu den hier genannten Elementen vgl. auch die Unterscheidung zwischen den Ereignissen und den Ereignisträgern Cic. inv. 1,34-41 (s. teilweise Kap. 2.1.2.2), wobei dort keine Instruktionen zur Erzeugung von Plausibilität gegeben werden. $\mathrm{Zu}$ ähnlichen Anweisungen zur Erzeugung von Plausibilität und Angemessenheit im Zusammenhang mit der Figurenrede vgl. Arist. rhet. 1408a25-36; Hor. ars 112-118; Quint. inst. 11,1,31-41; Plut. mor. 853d; Dionys. Hal. rhet. 11,3. 
spricht, als er gegen die Massageten zieht, oder Datis, als er nach der Schlacht bei Marathon mit dem König zusammentrifft. [. . .] Zuallererst muss man berücksichtigen, was für eine Person die sprechende Person ist und was für eine diejenige ist, an die sich die Rede richtet, das vorliegende Alter, die Gelegenheit, den Ort, den sozialen Status und den zugrunde liegenden Stoff, über den die beabsichtigten Worte gesprochen werden. Dann muss man schon versuchen, angemessene Worte zu sprechen. Denn aufgrund des Alters sind die einen oder die anderen Worte für die einen oder anderen angemessen, einem älteren und einem jüngeren Menschen ziemen nicht dieselben Worte, sondern wir werden die Rede des jüngeren Menschen mit Einfachheit und Klugheit vermischt sein lassen, diejenige des älteren Menschen mit Verstand und Erfahrung. Und aufgrund des Geschlechts sind für eine Frau und einen Mann wohl jeweils andere Reden angemessen, wegen des sozialen Status für einen Sklaven und einen frei geborenen Menschen, aufgrund des Berufes für einen Soldaten und einen Bauern, je nach Gefühlslage für einen verliebten und für einen beherrschten Menschen, und aufgrund der Abstammung sind die Worte des Spartaners anders, kurz und klar gehalten, und diejenigen des Mannes aus Attika anders, angenehm fließend. [. . .] Auch aufgrund der Orte und Gelegenheiten sind die Reden angemessen. Denn es werden nicht dieselben gehalten in der Heeresversammlung und in einer Versammlung von Bürgern, im Krieg und im Frieden, von Siegern und Besiegten, und was sonst noch alles mit den Personen zusammenhängt.]

Die Faktoren, die bei der Gestaltung der Figurenrede zu berücksichtigen sind, beziehen sich in erster Linie auf die Sprecher und in zweiter Linie auf die Angesprochenen. Dabei ergeben sich einige Faktoren aus der sprechenden (oder angesprochenen) Person selbst, wohingegen andere Parameter aus der Erzählung resultieren und daher mit den Elementen der Erzählung (s. Kap. 2.1.2.2) vergleichbar sind. Auf die Person selbst beziehen sich die folgenden Faktoren: ${ }^{224}$

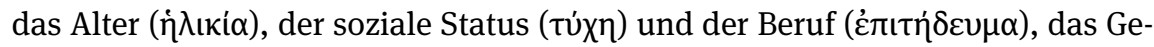

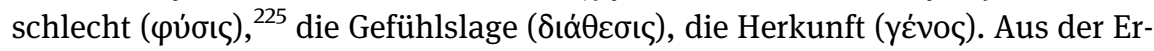

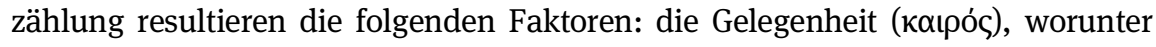
die Situation zu verstehen ist (z. B. Krieg oder Frieden), die sich mit der Zeit

224 Diese Faktoren sind teilweise mit den soziolinguistischen Parametern der modernen Linguistik vergleichbar (diagenerationeller, diastratischer, diasexueller und diatopischer Parameter). Einleitend unterscheidet Theon - gemäß der Unterscheidung zwischen der allgemeinen und der konkreten Fragestellung (s. Kap. 2.1.2.2) - zwischen unbestimmten und bestimmten Personen.

225 Inwiefern die Personen je nach Geschlecht unterschiedlich sprechen, wird von Theon nicht näher angegeben. Eine Stelle bei Plutarch (Plut. mor. 853d), an der dieser Aristophanes' Figurenreden kritisiert, legt die Vermutung nahe, dass die Einfachheit/Einfältigkeit (†ò $\dot{\pi} \lambda \lambda o u ̃ v)$ als Charakteristikum des weiblichen Geschlechts betrachtet wird. Zur Einfachheit/Einfältigkeit vgl. Theons

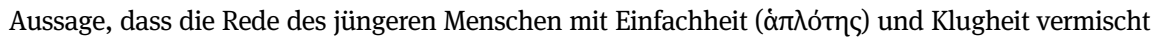
ist. Vgl. auch Aristoteles' Anforderung an die Figurenkonzeption, dass es für eine Frau nicht angemessen ist, so tapfer oder klug zu sein wie ein Mann (Arist. Poet. 1454a22-24); s. Kap. 2.1.4. 
(хро́voৎ) überschneiden oder sogar mit ihr identisch sein kann; ${ }^{226}$ der Ort (то́тоৎ); das Thema (ü $\lambda \eta)$.

Die Angabe „was sonst noch alles mit den Personen zusammenhängt“ erklärt sich dadurch, dass Theon bereits im Zusammenhang mit seinen Instruktionen zur Erzählung die Person als ein Element genannt und weiter untergliedert hat. Dort

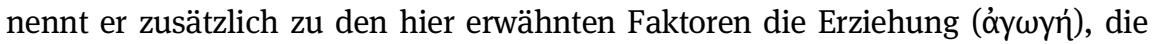

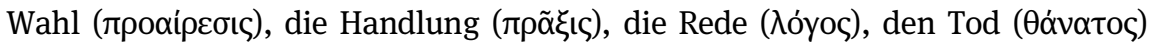

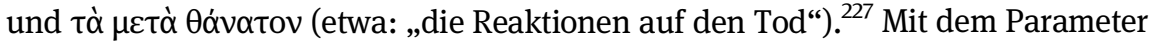

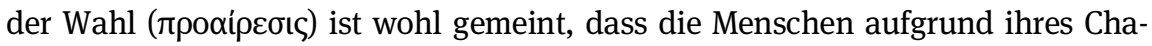
rakters die einen Dinge vorziehen und die anderen Dinge meiden. ${ }^{228}$ Der Tod trägt dem Umstand Rechnung, dass Personen z. B. einen heldenhaften Tod ster-

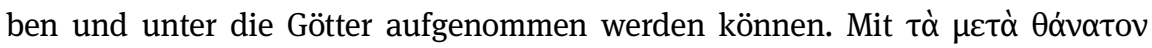
könnte der zuletzt genannte Umstand (das Nachleben) gemeint sein. Eher liegt die Bedeutung aber darin, was für eine Meinung die Menschen über den Verstorbenen haben. ${ }^{229}$ Die Berücksichtigung der beiden Parameter Tod und Reaktionen auf den Tod erklärt sich dadurch, dass in einer Figurenrede auch Tote reden können. ${ }^{230}$

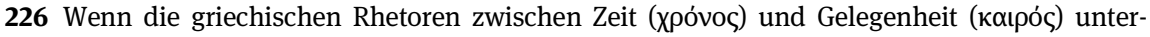
scheiden, wird der Unterschied nicht erklärt. Es scheint aber zwei Differenzkriterien zu geben: mit der Gelegenheit (кацро́) ist mehr als der Faktor Zeit gemeint (vgl. Patillon 2008, 202, Fn. 146); die Gelegenheit ist bestimmt, die Zeit hingegen unbestimmt. Dies geht aus (Pseudo-)

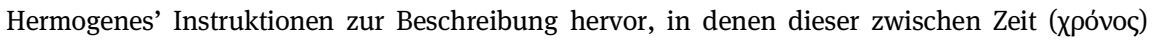
und Gelegenheit (каıрóৎ) unterscheidet, indem er Krieg und Frieden als Beispiele für die Gelegenheit und Frühling, Sommer und ein Fest / einen Festtag als Beispiele für die Zeit nennt und eine gemischte Beschreibung in einer Schlacht bei Nacht sieht, da eine Schlacht eine Handlung und die Nacht eine Gelegenheit ist; vgl. Hermog. Progym. 10,2f. Patillon (2008, 202). Vgl. auf der anderen Seite Aphthonios' Instruktionen zur Beschreibung, in denen nicht zwischen Zeit

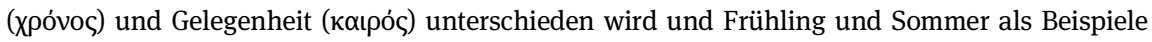

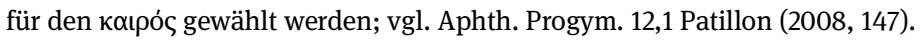

227 Vgl. Theon RhG II 78,24-26 Spengel (Patillon und Bolognesi 1997, 39).

228 Vgl. Arist. Poet. 1450b8-11.

229 Vgl. Theons (RhG II 110,10-12 Spengel; Patillon und Bolognesi 1997, 75) Reflexionen über Lob und Kritik, in denen er davon spricht, dass u. a. diejenigen Taten schön sind, die nach dem Tod gerühmt werden, da man lebenden Personen schmeichelt.

230 An anderen Stellen, an denen über die Figurenreden in der Geschichtsschreibung reflektiert wird, werden insbesondere die Personen (v. a. die sprechenden, teilweise auch die angesprochenen Personen) und die Situationen als Elemente genannt, die für die Gestaltung einer plausiblen Figurenrede berücksichtigt werden müssen; vgl. Thuk. 1,22,1 (s. Kap. 1.4.2.1); Dion. Hal. Thuk. 36 und 41; Marcellin. Vit. Thuc. 57; Luk. hist. conscr. 58; Feddern (2018, 151-158). 


\subsubsection{Zur Motivierung der Ereignisse in der Geschichtsschreibung}

Aristoteles' Gegenüberstellung der Aufgabe des Dichters und derjenigen des Historikers im neunten Kapitel der Poetik (s. Kap. 1.4.1.2) könnte so verstanden werden, dass die vom Historiker dargestellten Ereignisse (überhaupt) nicht kausal motiviert sind, da Aristoteles die Verknüpfung der Ereignisse im Sinn der Plausibilität bzw. Motivierung explizit nur zur Aufgabe des Dichters zählt (s. Kap. 2.1.3.1). Ferner gilt nach Aristoteles für den überwiegenden Teil der historischen und alläglichen Ereignisse, dass sie dem Zufall unterliegen, wenngleich nicht ausgeschlossen ist, dass sich einzelne Ereignisse kausal auseinander ergeben. Diese Ansicht äußert Aristoteles zum einen am Ende des ersten Teils des neunten Kapitels. ${ }^{231}$ Zum anderen stellt er im 23. Kapitel die Dichtung und die Geschichtsschreibung in der Hinsicht gegenüber, dass die dichterische - anders als die historiographische Darstellung eine organische Einheit bilden soll: ${ }^{232}$

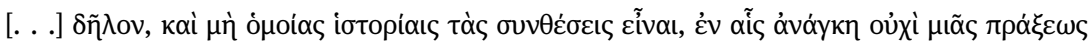

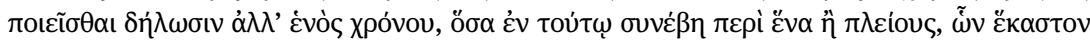

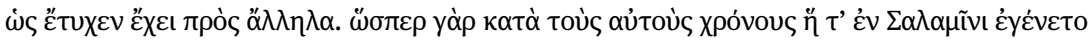

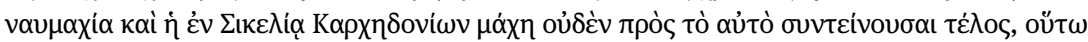

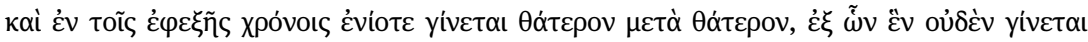

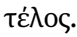

[[. . .] und es ist auch deutlich, dass die Zusammenstellungen [sc. der Ereignisse] nicht so sein dürfen wie in der Geschichtsschreibung, in der es nötig ist, eine Darstellung nicht einer Handlung, sondern eines Zeitraumes anzufertigen: was alles darin geschehen ist mit Blick auf einen oder mehrere, wovon sich ein jedes [sc. Ereignis] zueinander verhält, wie der Zufall es wollte. Denn so, wie sich zu derselben Zeit die Seeschlacht bei Salamis und die Schlacht gegen die Karthager auf Sizilien ereignete, ohne dass sie auf dasselbe Ziel gerichtet waren, so geschieht auch im Laufe der Zeit bisweilen das eine nach dem anderen, ohne dass sich hieraus ein einziges Ziel ergibt.]

Im Gegensatz zur einheitlichen Handlung der Dichtung zeichnet sich die Geschichtsschreibung also durch ihre fehlende innere Kohärenz aus, wie das Beispiel des Jahres 480 v.Chr. zeigt, in dem sowohl die Seeschlacht bei Salamis als auch die Schlacht bei Himera auf Sizilien stattgefunden hat, ohne dass sie in einem Kausalzusammenhang miteinander standen. ${ }^{233}$

Andere antike erzähltheoretische Reflexionen zeigen aber (und Aristoteles' Aussage, dass sich einzelne historische Ereignisse kausal auseinander ergeben,

231 Vgl. Arist. Poet. 1451b30-32; s. Kap. 1.4.1.2.

232 Arist. Poet. 1459a21-29.

233 Herodot $(7,166)$ berichtet, dass die Sizilianer behauptet haben, dass die beiden Schlachten an demselben Tag stattgefunden haben. Hierin ist wohl ein antiker Synchronismus zu sehen; vgl. Schmitt (2011, 672f.) ad Arist. Poet. 1459a21-29. 
deutet bereits darauf hin), dass auch für die faktualen Erzählgattungen die Motivierung der Ereignisse eine Rolle spielt und dass eher das Ausmaß der Motivierung ein Differenzkriterium zu den fiktionalen Erzählgattungen darstellt. So belegen die in der Herennius-Rhetorik erteilten Instruktionen zur Erzählung (narratio), dass der Redner gerade auch dann, wenn er die Wahrheit erzählt, auf eine plausible Darstellung der Ereignisse achten und ihre Gründe angeben muss (s. Kap. 2.1.3.2)..$^{234}$

Ferner gibt es auch geschichtstheoretische Passagen, die deutlich machen, dass der Historiker die Gründe für das Geschehen offenlegen muss. In Polybios' Aussagen über Phylarchos' Darstellung des Kleomenischen Krieges lässt sich erkennen, dass es als Defizit angesehen wurde, wenn die Gründe für die Entwicklung der Ereignisse unterschlagen wurden: ${ }^{235}$

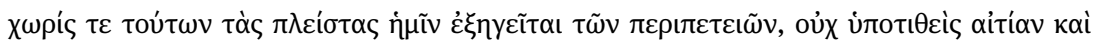

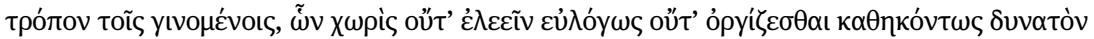

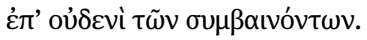

[Davon abgesehen erzählt er [sc. Phylarchos] uns die meisten Wechselfälle des Schicksals, ohne den Grund und die Art und Weise der Entwicklung anzugeben, ohne die es nicht möglich ist, bei irgendeinem Geschehnis in vernünftiger Weise Mitleid und angemessene Empörung zu empfinden.]

In der Forschung wurde und wird zwar die These diskutiert, ob Phylarchos ein Vertreter der sog. tragischen Geschichtsschreibung gewesen ist, die das Ziel der Tragödie, Angst und Mitleid zu erregen, in die Historiographie integriert habe (s. Kap. 3.2.1.3). Diese Diskussion ist aber für diesen Kontext wenig relevant, da Polybios seinem Vorgänger vorhält, einen handwerklichen historiographischen Fehler begangen $\mathrm{zu}$ haben, indem er den Grund für das Geschehen und seine nähere Entwicklung nicht mitgeteilt hat. Auch in seiner Timaios-Polemik (s. Kap. 2.1.1) erhebt Polybios den Vorwurf, dass jener Historiker nicht die Gründe für das Geschehen angibt, und erklärt das Gegenteil ebenso zum Charakteristikum der Geschichtsschreibung wie die Mitteilung der wirklich gehaltenen Reden: ${ }^{236}$

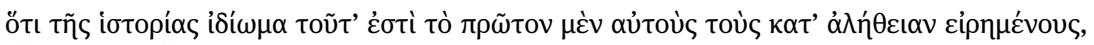

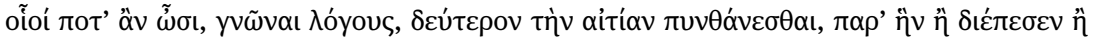

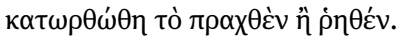

234 Auch zu den von Theon und anderen Verfassern von Progymnasmata-Handbüchern unterschiedenen sechs Elementen der Erzählung, die sich auf alle Erzählgattungen beziehen, gehört die Angabe der Gründe; s. Kap. 2.1.2.2.

235 Polyb. 2,56,13. Vgl. auch Polyb. 2,56,16 und 3,31,11-13.

236 Polyb. 12,25b1. 
[Die erste Kernaufgabe der Geschichtsschreibung besteht darin, die Reden selbst zur Kenntnis zu nehmen, die in Wahrheit gesprochen worden sind, wie auch immer sie sein mögen; die zweite darin, den Grund zu erfahren, aus dem geschehen ist oder ausgeführt wurde, was getan oder gesagt wurde.]

Auch in Ciceros rhetorischem Werk De oratore wird über die Geschichtsschreibung reflektiert und die Angabe der Gründe für das historische Geschehen als Anforderung an den Historiker formuliert, wenn der Ciceronische Antonius die Aufgaben des Geschichtsschreibers folgendermaßen skizziert: ${ }^{237}$

nam quis nescit primam esse historiae legem, ne quid falsi dicere audeat? deinde ne quid veri non audeat? ne quae suspicio gratiae sit in scribendo? ne quae simultatis? (63) haec scilicet fundamenta nota sunt omnibus, ipsa autem exaedificatio posita est in rebus et verbis: rerum ratio ordinem temporum desiderat, regionum descriptionem; vult etiam, quoniam in rebus magnis memoriaque dignis consilia primum, deinde acta, postea eventus exspectentur, et de consiliis significari quid scriptor probet et in rebus gestis declarari non solum quid actum aut dictum sit, sed etiam quo modo? et cum de eventu dicatur, ut causae explicentur omnes vel casus vel sapientiae vel temeritatis hominumque ipsorum non solum res gestae, sed etiam, qui fama ac nomine excellant, de cuiusque vita atque natura.

[Denn wer wüsste nicht, dass es das erste Gesetz der Geschichtsschreibung ist, dass sie nicht wagen soll, etwas Falsches zu sagen? Dann, dass sie nicht wagen soll, etwas Wahres zu verschweigen? Dass es keinen Verdacht auf Gefälligkeit im Schreiben geben soll? Dass es keinen Verdacht auf Feindschaft geben soll? (63) Diese Fundamente sind natürlich allen bekannt; die Konstruktion selbst aber liegt in den Dingen und in den Wörtern. Die Konzeption der Dinge erfordert eine chronologische Reihenfolge, eine Beschreibung der Regionen. Sie will auch, da in wichtigen und erinnerungswürdigen Dingen zuerst die Überlegungen, dann die Taten, schließlich die Ergebnisse erwartet werden, dass, was die Überlegungen betrifft, der Verfasser zu erkennen gibt, was er gutheißt, und dass bei den Taten nicht nur angegeben wird, was geschehen oder gesagt worden ist, sondern auch, auf welche Weise. Und wenn über den Ausgang gesprochen wird, dass alle Gründe erklärt werden entweder des Zufalls oder der Weisheit oder der Verwegenheit und nicht nur die Taten der Menschen selbst, sondern auch über das Leben und das Wesen eines jeden, der durch Ansehen und Namen hervorsticht, [sc. Angaben gemacht werden].]

Der Ciceronische Antonius nennt mehrere Aufgaben des Geschichtsschreibers, zu denen auch die Angabe der Gründe für das historische Geschehen gehört. Die Motivation des historischen Geschehens zeigt sich in der Aussage, dass zuerst die Überlegungen, dann die Taten und schließlich die Ergebnisse erwartet werden, da diese Ereignisse sicherlich nicht nur nacheinander folgen, sondern sich zumindest teilweise auseinander ergeben. Die Äußerung, dass bei den Taten nicht nur angegeben werden soll, was geschehen oder gesagt worden ist, sondern auch, auf welche Weise, ist als Forderung nach Ausführlichkeit zu verstehen, die zwar

237 Cic. de orat. 2,62f. Zu Ciceros Geschichtstheorie s. Kap. 1.4.2.1. 
nicht notwendigerweise auch die Gründe für das Geschehen umfassen muss, aber häufig beinhalten wird. ${ }^{238}$ Schließlich zeigen sich die Gründe für das historische Geschehen in der Instruktion, dass, wenn über das Resultat gesprochen wird, alle Gründe erklärt werden müssen - in Betracht kommt der Zufall oder das absichtsvolle menschliche Handeln (Weisheit oder Verwegenheit).

Daher wird es auch nach Ansicht des Aristoteles zu den Aufgaben des Historikers gehören, kein gänzlich unmotiviertes Geschehen zu schildern, und er wird unter der Geschichtsschreibung wohl nicht nur die Auflistung von historischen Ereignissen im Stil einer Chronik verstanden haben. ${ }^{239}$ Vielmehr ist das Ausmaß der Motivierung nach der Theorie der Geschichtsschreibung im Vergleich zur Motivierung der dichterischen Handlung geringer. Annäherungsweise lässt sich dieser Unterschied anhand von zwei Aspekten bemessen: Da die Geschichtsschreibung in der antiken Erzähltheorie grundsätzlich als Darstellung von wahren Sachverhalten, also als faktuale Erzählgattung, gilt (s. Kap. 1.4.2.1), darf der Historiker keine fiktionale Motivierung vornehmen, sondern muss diejenigen Gründe aufspüren und wiedergeben, die auch wirklich für das historische Geschehen verantwortlich sind (die sog. Tatsachenkonvention). In diesem Sinn spricht der Ciceronische Antonius davon, dass der Historiker alle Gründe für das historische Geschehen erklären muss, und zwar entweder des Zufalls oder der Weisheit oder der Verwegenheit. Mit anderen Worten: Wenn der Zufall für bestimmte Ereignisse verantwortlich ist, muss der Historiker eben dies angeben, und wenn die zielgerichteten Überlegungen, Reden und Taten der historischen Protagonisten verantwortlich sind, muss der Historiker eben diese Motivation der Ereignisse wiedergeben.

Ferner liegt die unterschiedliche Motivierung der historiographischen Darstellung und der dichterischen Handlung im Verhältnis vom Teil zum Ganzen. Das dichterische Werk zeichnet sich Aristoteles zufolge v. a. durch eine Zusammenstel-

238 Zur Forderung nach der Angabe von Grund sowie Art und Weise der historischen Ereignisentwicklung vgl. Polyb. 2,56,13 (s. Fn. 235); Sempronius Asellio apud Gell. 5,18,8 (HRF [Historicorum Romanorum Fragmenta] 109,1): nobis non modo satis esse video quod factum esset, id pronuntiare, sed etiam, quo consilio quaque ratione gesta essent, demonstrare [Ich sehe, dass es uns nicht ausreicht, nur zu verkünden, was geschehen ist, sondern [sc. dass es nötig ist,] auch zu zeigen, durch welchen Plan und auf welche Weise es geschehen ist.]; Dion. Hal. Ant. Rom. 5,56,1; Leeman et al. $(1985,268)$ ad Cic. de orat. 2,63; Avenarius (1954, 143f.).

$239 \mathrm{Zu}$ der umstrittenen Frage, wie adäquat Aristoteles' Bild von der Geschichtsschreibung ist, vgl. z. B. Ostwalds (2002, 9f.) Ansicht: Wenn man Aristoteles wörtlich nähme, bestünde die einzige Form der Geschichtsschreibung in der Annalistik, die z. B. im Werk der Atthidographen zum Vorschein kommt, die Ereignisse aufzählen, ohne sie miteinander zu verknüpfen. Auf Herodot und Thukydides würden Aristoteles' Aussagen nicht zutreffen. In Wirklichkeit würde die Arbeitsweise des Historikers im gleichen Maße wie diejenige des Tragödiendichters erfordern, die Ereignisse „nach Maßgabe des Wahrscheinlichen oder Notwendigen“ miteinander zu verknüpfen. 
lung einer einheitlichen Handlung durch die plausible Verknüpfung der Ereignisse im Zusammenspiel mit dem Charakter der handelnden Personen aus. Auf das ganze Werk gesehen, ist es in der Geschichtsschreibung in den meisten Fällen nicht möglich, eine ähnlich einheitliche und kausal motivierte Handlung zu schildern, da Aristoteles die Geschichtsschreibung als Darstellung eines Zeitraumes versteht und in einem Zeitraum die meisten Ereignisse zufällig geschehen. In einem kleineren Umfang, also bei einem Ereignis, ist die Schilderung einer einheitlichen und kausal motivierten Handlung hingegen möglich und nötig, sofern es der Wahrheit entspricht.

Die von Aristoteles gewählten Beispiele verdeutlichen diese Auffassung: Die Seeschlacht bei Salamis und die Schlacht bei Himera auf Sizilien haben zwar in demselben Jahr (480 v.Chr.) stattgefunden, aber sie haben - zumindest nach Aristoteles - insofern nichts miteinander zu tun, als kein gemeinsamer Grund für beide Schlachten ersichtlich ist. Dennoch ist davon auszugehen, dass es auch nach Aristoteles die Aufgabe des Historikers ist, bei den Einzelereignissen die Gründe für das Geschehen anzugeben: Für die Seeschlacht bei Salamis müssten die Gründe angeführt werden, die Anlass zu der Schlacht gegeben haben, der Verlauf der Schlacht und das Resultat müssten geschildert und erklärt werden, wobei auch der Zufall, v. a. aber das intentionale menschliche Handeln als treibende Faktoren dargestellt werden müssten.

Daher muss man Aristoteles' Auffassung von der Motivierung der Ereignisse in der Geschichtsschreibung wohl im Sinn einer Skala auffassen: Je näher man auf ein Einzelereignis blickt, desto kausal motivierter - und vergleichbarer mit der Dichtung - ist die historiographische Darstellung, wohingegen dies auf das ganze Werk gesehen zumeist nicht der Fall ist. ${ }^{240}$

\subsubsection{Die Figuren}

Von den Figuren als ein zentrales Element der Erzählung war bereits beiläufig die Rede (s. Kap. 2.1.2 und Kap. 2.1.3). In der modernen Erzähltheorie wird der Begriff der Figur mitunter auf Bewohner der fiktiven Welt fiktionaler Erzählungen

240 Somit unterscheidet Aristoteles zwar grundsätzlich anhand von zwei Differenzkriterien zwischen der Dichtung (insbesondere der Tragödie) und der Geschichtsschreibung, nämlich durch die Darstellung des Möglichen und die motivierte Ereignissequenz im Fall der Dichtung. Aber hinsichtlich dieser beiden Aspekte kann es zu Überschneidungen kommen, nämlich dann, wenn der Dichter unter dem Möglichen dasjenige wählt, was wirklich geschehen ist, und der Historiker eine kausal motivierte Darstellung eines Ereignisses oder einer Ereignissequenz wiedergibt (s. Kap. 1.4.1.2). 
beschränkt und in der Form dem Begriff der Person gegenübergestellt, dass Personen entweder von den Autoren faktualer Erzählungen dargestellt werden oder Menschen aus Fleisch und Blut sind, die in der realen Welt existieren. ${ }^{241}$

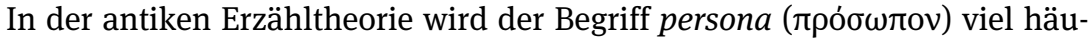

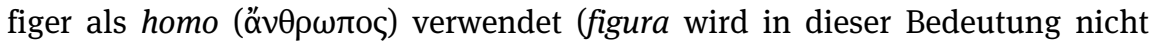
verwendet), und zwar in Bezug auf reale Menschen ebenso wie in Bezug auf fiktive Figuren, also indifferent gegenüber dem Parameter der Fiktion. Ferner

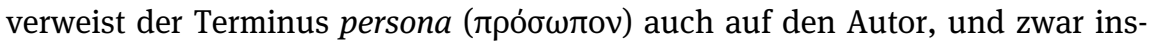

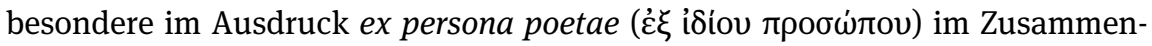
hang mit dem Redekriterium (s. Kap. 3.2.1 und 3.2.2) und der Fokalisierung

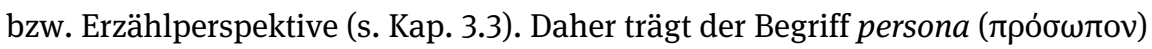
eine sehr weite Bedeutung, für die es kein deutsches Äquivalent gibt. Dieser Begriff wird hier grundsätzlich mit „Figur“ und dann behelfsweise mit „Person“ oder „Perspektive“ wiedergegeben, wenn das Redekriterium oder die Fokalisierung diskutiert wird. ${ }^{242}$

In der modernen Erzähltheorie wird die Kategorie der Figur durch mehrere Unterscheidungen und Aspekte beleuchtet, ${ }^{243}$ die teilweise schon in der antiken Erzähltheorie diskutiert wurden. ${ }^{244}$ So findet sich die Differenzierung zwischen menschlichen und nicht-menschlichen Handlungsträgern in einigen Progymnasmata-Handbüchern innerhalb der Instruktionen zur Fabel, in denen nach diesem Kriterium rationale, ethische und gemischte Fabeln unterschieden werden: ${ }^{245}$

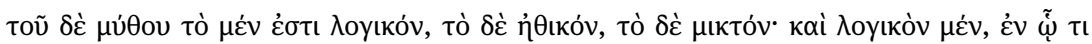

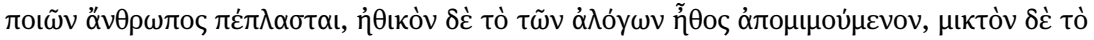

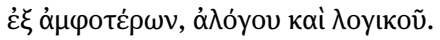

241 Vgl. Martinez und Scheffel (2016, 147).

242 Die Übersetzung mit „Figur“ erklärt sich dadurch, dass in dieser Monographie unter der Opposition zwischen einer Person und einer Figur der ontologische Unterschied verstanden wird, dass eine Person in der realen Welt lebt, wohingegen eine Figur in einem Erzähltext (oder in einem anderen Medium) dargestellt wird, und zwar unabhängig von der Frage, ob diese Figur erfunden ist oder real existiert (oder ein komplexeres Verhältnis zur Realität besteht). Denn dies scheint der am weitesten verbreitete Gebrauch dieser Begriffe zu sein. Außerdem vermischen sich in der fiktiven Welt immer Fakten und Fiktionen, so dass es problematisch wäre, auch eine historische Person in einer fiktionalen Erzählung als Figur zu bezeichnen, wenn man mit Figuren grundsätzlich fiktive Figuren meint.

243 Vgl. Martinez und Scheffel (2016, 147-153).

244 Zur Figur in der antiken Erzähltheorie und in antiken Erzähltexten vgl. Temmerman (2019). Zur antiken persona-Theorie und zum antiken Rollenverständnis s. Kap. 3.2.4 sowie die dort genannte Literatur.

245 Aphth. Progym. 1,2 Patillon (2008, 112). Vgl. auch Theon (RhG II 73,9-14 Spengel; Patillon und Bolognesi 1997, 31), dem eine ähnliche Unterteilung bekannt ist, aber wenig sinnvoll vorkommt, und Nikolaos (RhG XI 6,20-7,13 Felten), der anhand des Kriteriums der Handlungs- 
[Von der Fabel ist das eine rational, das andere ethisch und das andere gemischt. Rational ist, worin ein Mensch, der etwas tut, fingiert ist, ethisch ist dasjenige, was den Charakter von vernunftlosen [sc. Tieren und Dingen] nachahmt, gemischt ist dasjenige, was aus beidem, Vernunftlosem und Rationalem, besteht.]

In ähnlicher Form unterscheiden einige Verfasser von Progymnasmata-Handbüchern innerhalb der Anweisungen zur Figurenrede zwischen solchen, in denen Menschen als redend eingeführt werden (Ethopoiien), solchen, in denen Verstorbene sprechen (Eidolopoiien), und solchen, in denen Dinge - zumindest keine Menschen - als redend eingeführt werden (Prosopopoiien). ${ }^{246}$

Aristoteles lehrt im 15. Kapitel der Poetik, wie die Dichter den Charakter einer Figur konzipieren sollen, indem er vier Forderungen aufstellt. Hierin lässt sich punktuell eine antike Korrespondenz zur modernen Unterscheidung zwischen Figuren anhand ihrer Komplexität (Figuren sind mehr oder weniger komplex) und anhand ihrer Dynamik (Figuren können statisch oder dynamisch sein, indem sich ihre Persönlichkeitsmerkmale im Laufe der Erzählung mehr oder weniger ändern ${ }^{247}$ erblicken, wenngleich die Unterschiede die Gemeinsamkeiten überwiegen. Nach Aristoteles soll der Charakter erstens gut sein: ${ }^{248}$

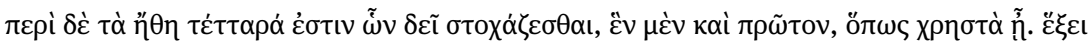

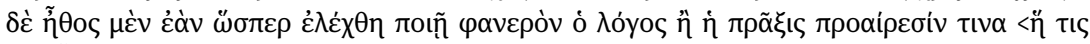

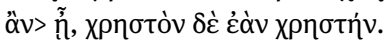

[Hinsichtlich der Charaktere gibt es vier Punkte, auf die man abzielen muss. Einer und der erste ist, dass sie gut sind. Charakter stellt sich ein, wenn - wie gesagt - die Rede oder Handlung eine bestimmte Tendenz deutlich macht, und wenn eine gute Tendenz, dann ein guter Charakter.]

träger die Äsopischen von anderen Fabeln unterscheidet (in den Äsopischen Fabeln treten rationale und irrationale Handlungsträger auf).

246 Vgl. Aphth. Progym. 11,1 Patillon (2008, 144); Hermog. Progym. 9,1 Patillon (2008, 200). Quintilian (Quint. inst. 9,2,29-37) und Theon (RhG II 115-118 Spengel; Patillon und Bolognesi 1997, 70-73) unterscheiden nicht zwischen der Prosopopoiie, der Ethopoiie und der Eidolopoiie; s. Kap. 2.1.3.2.

247 Vgl. Martinez und Scheffel (2016, 150f.).

248 Arist. Poet. 1454a16-19. Für das Postulat, dass die Charaktere gut sein sollen, vgl. Aristoteles' Instruktion im fünften Kapitel der Poetik, dass die Komödie zwar die Darstellung von schlechteren Menschen (als der Durchschnittsmensch) ist, aber nicht von der Verdorbenheit schlechthin (Arist. Poet. 1449a32-37). Zum Charakter als Tendenz, bestimmte Dinge zu meiden und andere vorzuziehen, vgl. Arist. Poet. 1450b8-11. 
Die zweite Anforderung besteht darin, dass der Charakter angemessen sein soll, womit gemeint ist, dass das Verhalten zum Charakter passen soll: ${ }^{249}$

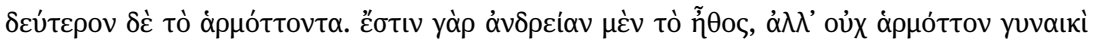

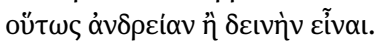

[Das Zweite ist die Angemessenheit. Es ist möglich für eine Frau, hinsichtlich des Charakters tapfer zu sein, aber es ist nicht angemessen, so tapfer oder klug zu sein [sc. wie ein Mann].]

Drittens soll der Charakter dem Durchschnittsmenschen ähnlich sein: ${ }^{250}$

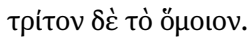

[Das Dritte ist die Ähnlichkeit.]

Diese Forderung hängt mit dem ersten Postulat und den Zielen der mimetischen Dichtung, insbesondere der Tragödie, zusammen: Da Angst und Mitleid die tragödienspezifischen Wirkungen sind, können sich diese nur entfalten, wenn die dargestellten Figuren dem Durchschnittsmenschen ähnlich sind, da niemand Angst hat um einen verkommenen Menschen (und davor, dass ein ähnliches Unglück einen selbst befallen könnte), der vom Glück ins Unglück stürzt. ${ }^{251}$

Und viertens soll der Charakter konsistent sein: ${ }^{252}$

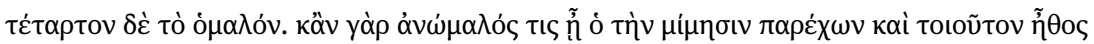

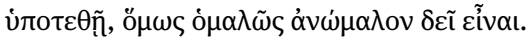

[Das Vierte ist die Konsistenz. Denn auch wenn derjenige inkonsistent sein sollte, der Anlass zur Nachahmung bietet, und einen derartigen Charakter aufweist, muss er trotzdem in konsistenter Weise inkonsistent sein.]

Mit Blick auf die moderne Figuren-Differenzierung anhand ihrer Komplexität und Dynamik ergeben sich gerade in dieser vierten Forderung Berührungspunkte bzw. lohnt sich ein Vergleich. Auch wenn es nicht Aristoteles' Vorstellungen entsprechen wird, dass eine Figur gänzlich statisch ist, scheint sein Ideal eher ein statischer Charakter zu sein, da sich die Persönlichkeitsmerkmale im Laufe der Erzählung bzw. der Tragödie kaum ändern, zumindest nicht widersprechen sol-

249 Arist. Poet. 1454a22-24. Vgl. auch die Besprechung des Negativbeispiels Arist. Poet. 1454a29-31.

250 Arist. Poet. 1454a24.

251 Vgl. Arist. Poet. 1453a2-7.

252 Arist. Poet. 1454a26-28. 
len. Vorstellbar wäre allenfalls, dass sich verschiedene Charakterzüge derselben Person zeigen. Dies zeigt auch das von ihm kritisierte Negativbeispiel: ${ }^{253}$

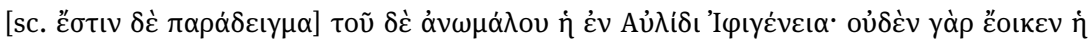

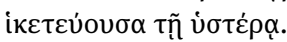

[Ein Beispiel für die Inkonsistenz ist die Iphigenie in Aulis. Denn die flehentlich bittende Iphigenie sieht der späteren überhaupt nicht ähnlich.]

Die Iphigenie, wie Euripides sie in seiner Tragödie gestaltet, ist nach Aristoteles' Urteil zu wenig konsistent, da sie erst ihren Vater Agamemnon flehentlich darum bittet, nicht geopfert zu werden, und sich dann bereit erklärt, den Tod auf sich zu nehmen, damit die griechische Flotte nach Troja segeln kann. ${ }^{254}$

Daher sind Aristoteles' Ideal und sein Bild von den Figuren der Homerischen Epen und der Attischen Tragödie, das diesem Ideal nicht sehr fern stehen wird (die Negativbeispiele dürften eher Ausnahmen von der Regel sein), wohl so zu verstehen, dass die Figuren eher komplex (Achill ist jähzornig, tapfer, hilfsbereit, wehleidig und mitleidig zugleich), ${ }^{255}$ aber konsistent und somit eher statisch sind bzw. sein sollen.

Sehr ähnliche Anweisungen zur Gestaltung der Charaktere erteilt Horaz in seiner Ars poetica. So fordert er wie Aristoteles, dass die Figuren konsistent sein sollen, wobei er diese figurenbezogene Forderung aus einem allgemeineren Postulat ableitet, das auch die Komposition der Handlung umfasst: $:^{256}$

aut famam sequere aut sibi convenientia finge scriptor. thonoratumt si forte reponis Achillem,

impiger, iracundus, inexorabilis, acer iura neget sibi nata, nihil non arroget armis. sit Medea ferox invictaque, flebilis Ino, perfidus Ixion, Io vaga, tristis Orestes. siquid inexpertum scaenae committis et audes personam formare novam, servetur ad imum qualis ab incepto processerit et sibi constet.

253 Arist. Poet. 1454a31-33.

254 Vgl. Schmitt (2011, 533).

255 Vgl. Schmitt $(2011,531)$.

256 Hor. ars 119-127. Für den grundlegenden Wert, den Horaz der Stimmigkeit zuweist, vgl. den Anfang der Ars poetica (V. 1-23) und V. 151f. Zu V. 120-127 vgl. Kozák (2014); Gualandri (2009). Zu V. 120 vgl. Pozdnev (2015). Ob scriptor als Vokativ zu Vers 119 oder als Prädikativum zum folgenden Satz gehört, lässt sich nicht entscheiden; zu dieser Frage vgl. Brink (1971, 199). Zur Ars poetica allgemein s. Kap. 2.1.1. 
[Folge entweder der Tradition oder erfinde etwas, was stimmig ist, Autor. Wenn du nun den tangesehenen† Achill wieder vorkommen lässt, soll er rastlos, zornig, unnachgiebig und ungestüm leugnen, dass das Recht für ihn gemacht wurde, soll er sich mit Waffengewalt alles ohne Ausnahme anmaßen. Medea soll wild und unbezähmbar sein, Ino weinerlich, Ixion hinterhältig, Io umherirrend, Orest Trauer verbreitend. Wenn du aber etwas, was vorher noch nicht versucht wurde, der Bühne anvertraust und es wagst, eine neue Figur zu gestalten, soll sie bis zum Ende so bleiben, wie sie von Anfang an in Erscheinung getreten ist, und konstant sein.]

Ähnlich wie Aristoteles schwebt Horaz ein eher komplexer Charakter vor Augen, der sich selbst treu bleiben soll, wie insbesondere das Beispiel des Achill zeigt, der u. a. als rastlos, zornig, unnachgiebig und ungestüm dargestellt werden soll.

Ferner erteilt Horaz die Anweisung, dass das Verhalten der Figuren ihnen angemessen sein soll: $:^{257}$

qui didicit, patriae quid debeat et quid amicis, quo sit amore parens, quo frater amandus et hospes, quod sit conscripti, quod iudicis officium, quae partes in bellum missi ducis, ille profecto 315 reddere personae scit convenientia cuique. respicere exemplar vitae morumque iubebo doctum imitatorem et vivas hinc ducere voces.

[Wer gelernt hat, was er dem Vaterland schuldet und was den Freunden, mit welcher Liebe der Vater / die Mutter, mit welcher der Bruder und der Gastfreund geliebt werden muss, was die Pflicht des Senators, was diejenige des Richters ist, welche Rolle diejenige des Anführers ist, der in den Krieg geschickt wurde, der weiß in der Tat, einer jeden Figur das Passende zu geben. Ich werde befehlen, dass der gelehrte Nachahmer ein Vorbild des Lebens und des Charakters betrachtet und von hier lebendige Äußerungen herleitet.]

Der gelehrte Dichter soll also aufgrund seiner Menschenkenntnis und seines Weltwissens in der Lage sein, Figuren zu konzipieren, deren Verhalten ihnen angemessen ist.

Die Angemessenheit der Figuren kommt in der antiken Erzähltheorie auch in der Form zum Vorschein, dass fiktive Figuren als so gestaltet wahrgenommen werden, dass die Interaktion mit einer als historisch betrachteten Figur angemessen und plausibel wirkt. Dies zeigt sich an Ciceros Überlegungen über die Begegnung zwischen Odysseus und den Sirenen: ${ }^{258}$

[. . . ] mihi quidem Homerus huius modi quiddam vidisse videatur in iis, quae de Sirenum cantibus finxerit. neque enim vocum suavitate videntur aut novitate quadam et varietate

257 Hor. ars 312-318. Vgl. hierzu Sedley (2014).

258 Cic. fin. 5,49. 
cantandi revocare eos solitae, qui praetervehebantur, sed quia multa se scire profitebantur, ut homines ad earum saxa discendi cupiditate adhaerescerent. ita enim invitant Ulixem nam verti, ut quaedam Homeri, sic istum ipsum locum [. . .]. vidit Homerus probari fabulam non posse, si cantiunculis tantus irretitus vir teneretur.

[[. . . ] mir jedenfalls scheint Homer etwas von dieser Art in dem erkannt zu haben, was er über den Gesang der Sirenen gedichtet hat. Denn sie pflegten offenbar nicht durch die Süße ihrer Stimmen oder durch eine neue und abwechslungsreiche Art zu singen diejenigen, die vorbeifuhren, zurückzurufen, sondern weil sie verkündeten, sie wüssten vieles, so dass die Menschen aus Begierde nach Erkenntnis an ihren Felsen strandeten. So nämlich laden sie Odysseus ein. Denn ich habe - wie einige Homerische Passagen - so auch diese Stelle selbst übersetzt [. . .]. Homer hat gesehen, dass die Geschichte nicht plausibel gemacht werden könnte, wenn ein so großer Mann durch leeren Gesang auf- und festgehalten würde.]

Diese Reflexionen gehören zu einem philosophischen Kontext, in dem darüber diskutiert wird, dass den Menschen eine immense Wissbegierde angeboren ist und sie sich daran erfreuen, etwas zu lernen. ${ }^{259}$ Diese Tatsache komme auch an einer Stelle der Odyssee zum Vorschein. Homer hat nämlich nach Ansicht des Sprechers die phantastische Passage mit Odysseus und den Sirenen zwar frei erfunden. ${ }^{260} \mathrm{Er}$ hat diese Begegnung aber nicht irgendwie gestaltet, sondern der als historisch betrachteten Figur Odysseus dadurch Rechnung getragen, dass er die Sirenen als allwissende Gestalten fingiert hat: ${ }^{261}$ Da sich ein Mensch, v. a. ein bedeutender Mann wie Odysseus, nicht lange mit unbedeutendem Gesang aufhalten würde, aber durch die Aussicht, Wissen zu erlangen, angelockt werden würde, hat Homer durch das umfassende Wissen der Sirenen den Faktor der Angemessenheit berücksichtigt, da nur so die Interaktion zwischen Odysseus und den Sirenen plausibel und Odysseus' Verhalten ihm selbst angemessen ist.

\subsubsection{Die rezeptionsorientierte Lösung von Problemen}

In der antiken Erzähltheorie finden sich auch hermeneutische Überlegungen in der Form, dass aus dezidiert rezeptionsorientierter Perspektive danach gefragt

259 Vgl. Cic. fin. 5,48-51.

260 Die Sirenen sind Fabelwesen, die den Kopf einer Frau, aber den Körper eines Vogels hatten; vgl. Hom. Od. 12,39-54 und 158-200. Ihre Fiktivität wird im antiken Fiktionalitätsdiskurs

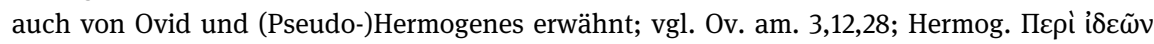
hóyou 2,10,37-41 Patillon (2012, 212f.).

261 In der Übersetzung des Sprechers behaupten die Sirenen von sich: omniaque e latis rerum vestigia terris [sc. tenemus] [sowie alle Spuren der Dinge aus der weiten Welt [sc. kennen wir]]; vgl. Hom. Od. 12,191. 
wird, wie sich Probleme eines Erzähltextes lösen lassen. Einschlägige Texte, in denen diese Frage relativ allgemein erörtert wird, sind das 25. Kapitel der Aristotelischen Poetik, in dem Probleme und Lösungen im Zusammenhang mit dichterischen Werken besprochen werden (Kap. 2.1.5.1); Plutarchs Essay De audiendis poetis (etwa: „Wie die jungen Menschen die Dichtung rezipieren sollen“) (Kap. 2.1.5.2); und Kommentare und Scholien wie Porphyrios' Homerprobleme (Kap. 2.1.5.3). Wie es kaum anders zu erwarten ist, bestehen viele Übereinstimmungen zwischen den in den vorigen Kapiteln präsentierten Elementen der Erzählung, die (eher) produktionsorientiert formuliert werden, und den rezeptionsorientierten Überlegungen, die den pragmatischen Kontext der Erzählung betreffen und insbesondere die handelnden und/oder sprechenden Figuren in den Blick nehmen. ${ }^{262}$ Sofern diese Reflexionen den Unterschied zwischen der Autor- und der Figurenrede zur Lösung von Problemen des Erzähltextes nutzbar machen, werden diese Interpretationen in Kapitel 3.2.2 dieser Monographie behandelt.

\subsubsection{Aristoteles' Lösung von Problemen}

Aristoteles lehrt im 25. Kapitel der Poetik, dass sich einige vermeintliche Probleme, die Rezipienten in dichterischen Erzählungen sehen, dadurch lösen, dass man die Zeit, zu der die Erzählung spielt, berücksichtigt. Die Diskussion dieser Problemlösung folgt auf Aristoteles' am Anfang des 25. Kapitels genanntes Prinzip, dass die Dichter entweder etwas so darstellen, wie es war oder ist, oder so, wie es der allgemeinen Vorstellung entspricht, oder so, wie es sein müsste: ${ }^{263}$

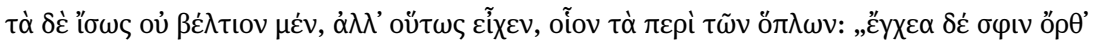

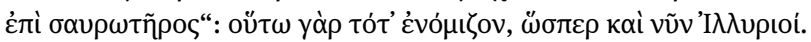

[Anderes ist zwar vielleicht nicht besser, aber hat sich so verhalten, wie dasjenige über die Waffen: „Sie hatten die Lanzen senkrecht auf der Schaftspitze stehen.“ So war es nämlich damals üblich, wie es auch jetzt die Illyrer machen.]

Da die Möglichkeit besteht, dass die sich in Homers Ilias findende Aussage, dass die Kämpfer die Lanzen senkrecht auf der Schaftspitze stehen hatten, ${ }^{264}$ Probleme bereitet, erklärt Aristoteles diese irritierende Aussage durch die Be-

262 Zum Kontext in der antiken Literaturtheorie vgl. Nünlist (2018), der sowohl aus onomasio-

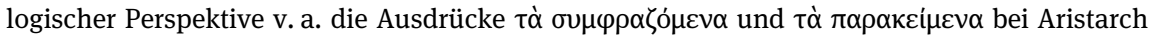
und Plutarch untersucht als auch semasiologische Beobachtungen anstellt. Zu modernen Kontextkonzepten und ihrer Anwendung auf die antike Literatur vgl. Tischer et al. (2018). Zur Interpretation im antiken Rom vgl. Vogt-Spira (2015). Zu Aristarch vgl. Schironi (2009).

263 Arist. Poet. 1461a2-4. Zum am Anfang des 25. Kapitels genannten Prinzip vgl. Arist. Poet. 1460b8-11.

264 Vgl. Hom. Il. 10,152f. 
rücksichtigung der Zeit der Erzählung (und sekundär durch einen Hinweis auf eine andere ethnische Gruppe und somit einen anderen Kulturraum): Damals, also zumindest zu Homers Zeit (nach antiker Vorstellung: 914 v.Chr. oder noch früher), ${ }^{265}$ eher sogar zum Zeitpunkt der Erzählung (dem Trojanischen Krieg: 2. Hälfte des dreizehnten Jahrhunderts v.Chr.), war es üblich, dass die Lanzen mit dem Schaft im Boden steckten. ${ }^{266}$

Weitere Faktoren, die die Kontextualisierung der dichterischen Erzählung betreffen, diskutiert Aristoteles an der folgenden Stelle, an der er mit Blick auf einen möglichen Vorwurf an die Dichter die folgende Erwiderung empfiehlt: ${ }^{267}$

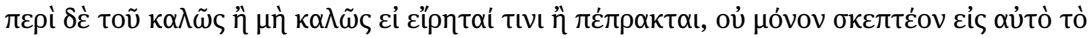
$\pi \varepsilon \pi \rho \alpha y \mu \varepsilon$ vov

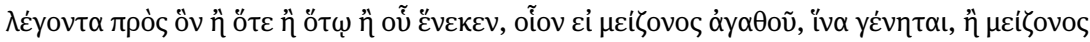

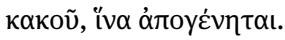

[Hinsichtlich der Frage, ob jemand etwas gut oder nicht gut gesagt oder getan hat, darf man nicht nur auf das Getane oder Gesagte blicken und prüfen, ob es gut oder mangelhaft ist, sondern muss auch auf den Handelnden oder Sprechenden blicken und prüfen, wem gegenüber oder wann oder für wen oder weswegen [sc. er handelt oder spricht], z. B. ob er es wegen eines größeren Gutes tut, damit es eintritt, oder eines größeren Übels, damit es abgewendet wird.]

Aristoteles empfiehlt also, zur Lösung eines moralischen Problems den Kontext der dichterischen Erzählung insofern zu berücksichtigen, als neben dem Ereignis (Handlung oder Rede) auch die ausführende Person, die betroffene Person, die Zeit, die bevorteilte Person und der Grund eine wichtige Rolle spielen.

Ferner behandelt Aristoteles weitere Möglichkeiten der Problem-Lösung, die hier nur erwähnt, aber nicht präsentiert werden sollen, da sie sprachlichstilistische Phänomene wie Metaphern in den Blick nehmen. ${ }^{268}$

\subsubsection{Plutarchs Lösung von Problemen}

In Plutarchs Essay De audiendis poetis lässt sich ebenfalls insofern eine Kontextualisierung der Erzählung, nämlich der unter ethischen Gesichtspunkten problematischen Dichterstellen, erkennen, als der Kontext, insbesondere der Charakter

265 Vgl. Cic. rep. 2,18. Diese Berechnung ergibt sich, wenn man das Jahr 776 v.Chr. als Datum der ersten Olympiade ansetzt.

266 Vgl. Schmitt (2011, 714). Vgl. auch Aristarchs Homer-Erklärungen, die das Anliegen offenbaren, den historischen Kontext der Erzählung dem hellenistischen Lesepublikum näherzubringen; vgl. Nünlist $(2018,116)$.

267 Arist. Poet. 1461a4-9.

268 Vgl. Arist. Poet. 1461a9-b9. 
der handelnden Person, aber auch die Situation, zur Lösung des Problems herangezogen wird. ${ }^{269}$ Besonders deutlich wird Plutarchs Lehre von der Kontextualisierung im achten Kapitel des Essays, in dem dieser die Handlungen von Achill und Agamemnon diskutiert, wie sie am Anfang von Homers Ilias geschildert werden. Dabei geht er von dem Grundsatz aus, dass die Dichtung eine Nachahmung des menschlichen Lebens ist und die Menschen nicht perfekt sind, so dass auch moralisch anstößige Handlungen erzählt werden (s. Kap. 3.2.3): ${ }^{270}$

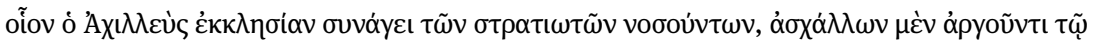

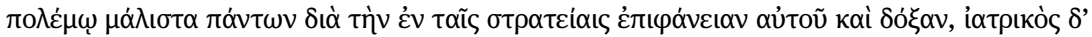

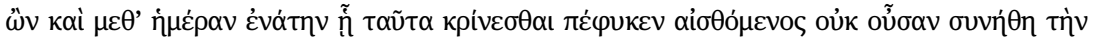

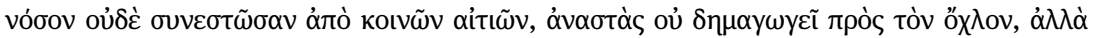

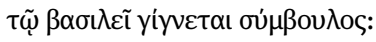

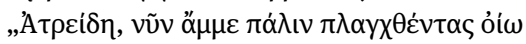

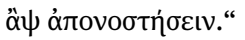

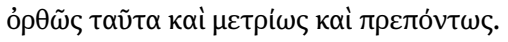

[Zum Beispiel beruft Achill eine Versammlung der kranken Soldaten ein, da er von allen am meisten über den ins Stocken geratenen Krieg unzufrieden ist wegen seines Ansehens und seines Ruhmes in Kriegsdingen; da er ein Arzt ist und nach dem neunten Tag, an dem dies von Natur aus seinen Höhepunkt erreicht, merkt, dass die Krankheit nicht gewöhnlich ist und nicht aus normalen Gründen entstanden ist, steht er nicht auf und biedert sich dem Volk an, sondern berät den König: „Atride, ich zumindest glaube, dass wir jetzt wieder aufbrechen und zurück nach Hause gehen.“ Das sagt er richtig, maßvoll und angemessen.]

Plutarch erklärt und lobt also Achills Verhalten in diesem Kontext, da der (nicht unproblematische) Held von seinem Charakter her am meisten auf einen erfolgreichen Krieg bedacht ist und in der gegebenen Situation, in der die Griechen von einer Pest heimgesucht werden, aufgrund seiner medizinischen Kenntnisse besorgt ist und taktvoll dem Anführer Agamemnon den Rat gibt, dass die Griechen heimkehren sollten.

Anders beurteilt Plutarch hingegen das sich in der Erzählung anschließende Verhalten Achills::271

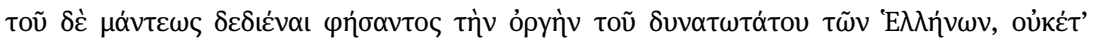

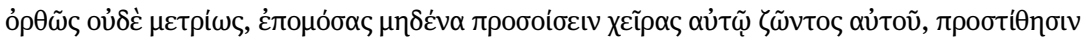

$269 \mathrm{Zu}$ Plutarchs Essay De audiendis poetis vgl. den Kommentar von Hunter und Russell (2011) und die zweisprachige Loeb-Ausgabe (mit englischer Übersetzung) von Babbitt (1960). Zur Erziehung bei Plutarch vgl. Xenophontos (2015). Zur Tragödie bei Plutarch vgl. di Gregorio (1976). Zur Dichtung bei Plutarch vgl. Valgiglio (1967). Zu den klassischen Dichtern bei Plutarch vgl. Schläpfer (1950).

270 Plut. mor. 26b-c. Zum Kontext vgl. Plut. mor. 26a-b. Zum Homerzitat vgl. Hom. Il. 1,59f. 271 Plut. mor. 26d. Zum Homerzitat vgl. Hom. Il. 1,90. 


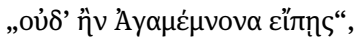

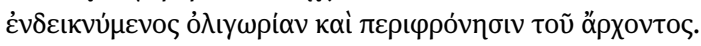

[Nachdem aber der Seher gesagt hat, dass er den Zorn des mächtigsten Mannes der Griechen fürchtet, und er [sc. Achill] geschworen hat, dass niemand die Hände gegen ihn [sc. den Seher] erheben wird, solange er [sc. Achill] lebt, fügt er nicht mehr richtig und maßvoll hinzu „selbst wenn du Agamemnon [sc. als Schuldigen] nennen solltest“, womit er seine Geringschätzung und Verachtung des Herrschers zeigt.]

Plutarch kritisiert den Homerischen Achill für diese Äußerung, weil dieser Agamemnons Vorrangstellung nicht beachte. Ob dieses Verständnis dem Erzähltext gerecht wird, ist allerdings fraglich, da es auch möglich ist, dass Agamemnons Sonderstellung hervorgehoben werden soll. ${ }^{272}$

Auch im weiteren Verlauf der Konfrontation zwischen Achill und Agamemnon sieht Plutarch sowohl vorbildliches als auch verwerfliches Verhalten des ersteren Kriegers: ${ }^{273}$

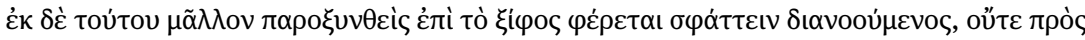

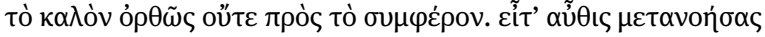

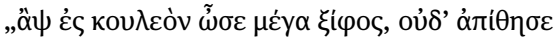

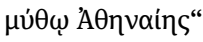

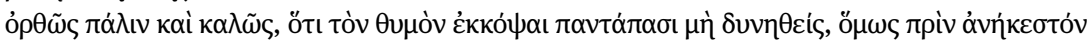

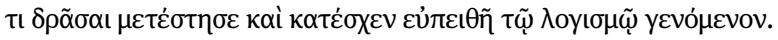

[Danach wird er, weil er im stärkeren Maß provoziert wird, zum [sc. Ergreifen des] Schwertes verleitet in der Absicht, einen Mord auszuüben - das macht er nicht richtig, weder hinsichtlich des Guten noch hinsichtlich des Nützlichen. Dann wieder aus Reue „steckte er das große Schwert zurück in die Schwertscheide und befolgte Athenes Wort“ - das macht er wiederum richtig und schön, weil er, obwohl er seine Wut nicht gänzlich unterdrücken konnte, dennoch, bevor er etwas tat, was nicht rückgängig gemacht werden konnte, sie aufgab und kontrollierte, indem sie der Vernunft gehorchte.]

Plutarch berücksichtigt also den Umstand, dass Achill von Agamemnon provoziert wird, indem der Anführer der Griechen Achill in einem Wortgefecht damit droht, dessen Sklavin Briseis in seinen Besitz zu nehmen als Kompensation für Chryseis, die er ihrem Vater zurückgeben muss, damit die Pest endet. Plutarch kritisiert aber Achills Reaktion, nämlich dass er zum Schwert greift in der Absicht, Agamemnon zu töten, obwohl diese Tat moralisch verwerflich und für die vor Troja kämpfenden Griechen kontraproduktiv wäre. Auf der anderen

272 Vgl. Hunter und Russell $(2011,149)$.

273 Plut. mor. 26d-e. Zum Homerzitat vgl. Hom. Il. 1,220 f. 
Seite lobt er Achill dafür, dass er auf Athenes mahnende Worte hin seinen wütenden Impuls kontrolliert und der Vernunft unterordnet. ${ }^{274}$

In ähnlicher Weise beurteilt Plutarch Agamemnons Verhalten als dasjenige, das einem König mal mehr und mal weniger gerecht wird und teilweise den Umständen geschuldet ist: ${ }^{275}$

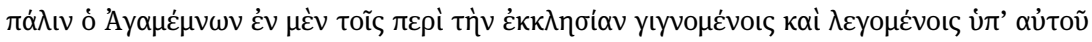

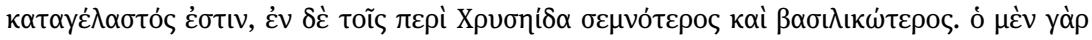

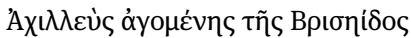

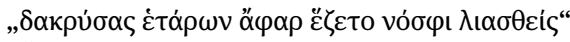

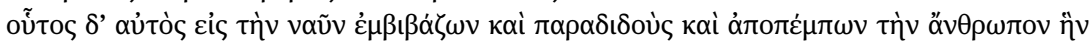
ỏ入íy

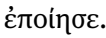

[Agamemnon wiederum ist zwar in demjenigen, was er im Zusammenhang mit der Versammlung tut und sagt, lächerlich, im Zusammenhang mit Chryseis aber erhabener und königlicher. Achill nämlich, als Briseis fortgebracht wurde, „weinte und saß sogleich zurückgezogen von seinen Freunden da“; dieser aber machte nichts Erotisches oder Schimpfliches, als er die Sklavin, von der er kurz zuvor gesagt hatte, dass er sie in seiner Gunst seiner Ehefrau vorzieht, selbst zum Schiff brachte, übergab und fortschickte.]

Agamemnon verhält sich also Plutarch zufolge lächerlich, wenn er sich mit Achill in der Versammlung streitet, wirkt aber souveräner, wenn er Chryseis fortschickt, ${ }^{276}$ obwohl er sie höher schätzt als seine Frau Klytaimestra. ${ }^{277}$ Denn so wird er seiner Verantwortung für die Griechen gerecht, die von der Pest heimgesucht werden, weil Agamemnon den Apollon-Priester Chryses abschätzig behandelt hat, als dieser um die Freigabe seiner Tochter bat. ${ }^{278}$ Achill hingegen zieht sich zurück und weint, als seine Sklavin Briseis aus seinem Zelt in dasjenige des Heerführers gebracht wird.

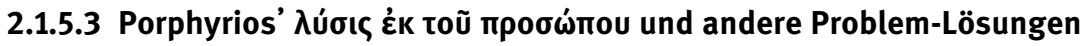

Porphyrios (drittes Jahrhundert n.Chr.) löst mit dem Konzept der „(Problem-)

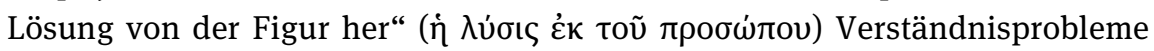
der Homerischen Epen, insbesondere ethisch anstößige Stellen und vermeintliche Widersprüche, durch die Berücksichtigung der handelnden und/oder sprechenden Figur. Mit dem modernen Konzept des Ortes des Erzählens oder

274 Vgl. Hunter und Russell (2011, 149f.); Hom. Il. 1,188-222.

275 Plut. mor. 26e-f. Zum Homerzitat vgl. Hom. Il. 1,349.

276 Vgl. Hom. Il. 1,308-311.

277 Vgl. Hom. Il. 1,112-115.

278 Vgl. Hom. Il. 1,11-32. 


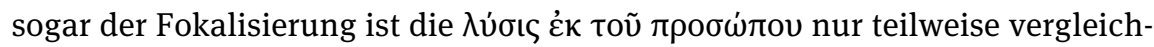
bar, da sie insofern weiter gefasst ist, als auch die handelnden Figuren in den Blick genommen werden und somit die Unterscheidung zwischen der Autorund der Figurenrede (oder sogar eine weitere Differenzierung auf der Ebene der Figurenreden) nur ein Teilaspekt dieses Konzeptes ist (zu diesem Teilaspekt s. Kap. 3.2.2). ${ }^{279}$

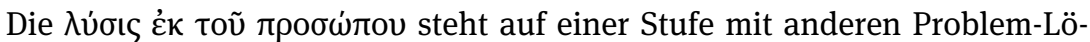

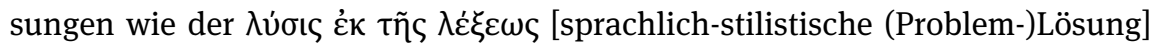

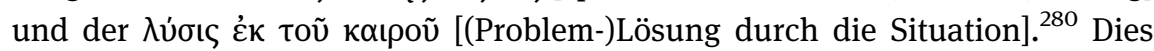
führt paradigmatisch diejenige Stelle vor Augen, an der Porphyrios das Problem behandelt, dass der Priester Chryses am Anfang der Ilias Apoll bittet, dass er mit seinen Pfeilen Verderben über das Heer der Griechen bringen möge, da deren Anführer Agamemnon sich geweigert hat, ihm seine Tochter Chryseis im Austausch mit Geschenken zurückzugeben: ${ }^{281}$

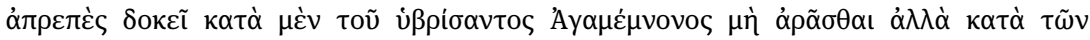

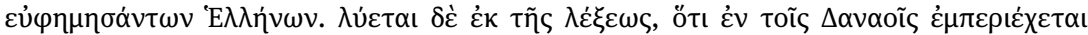

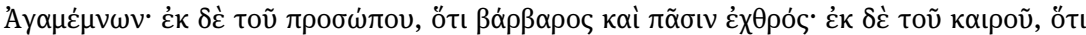

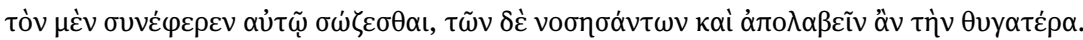

[Es erscheint unangemessen, die Bitte nicht gegen Agamemnon, der ihn arrogant behandelt hat, sondern gegen die Griechen zu richten, die ihm Ehre erwiesen haben. [sc. Dieses Problem] löst sich aber von der Sprache her, weil in den „Danaern“ [sc. „Griechen“] Agamemnon enthalten ist; von der Person her, weil er ein Barbar und allen ein Feind ist; von der Situation her, weil es ihm nützen würde, dass der eine wohlbehalten bleibt und, wenn die anderen krank sind, er seine Tochter zurückbekommt.]

Porphyrios bietet drei mögliche Lösungen des Problems an, dass Chryses Apoll darum bittet, dass dieser nicht (nur) Agamemnon, sondern die Griechen heimsuchen möge: die sprachliche Erklärung, dass im Begriff der „Danaer“ („Griechen“) auch Agamemnon enthalten bzw. impliziert ist; die „(Problem-)Lösung von der Figur her“, der zufolge der Trojaner Chryses als Barbar allen feindlich gesinnt ist; und die Erklärung durch die Situation, dass Chryses sein Ziel erreichen könnte,

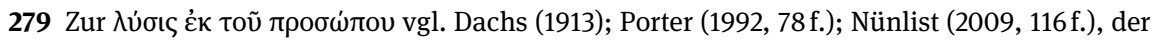
dieses Konzept in einem Kapitel zur Fokalisierung behandelt, mit weiterer Literatur (116, Fn. 2); Schmidt (1976, 24, Fn. 48) mit weiterer Literatur.

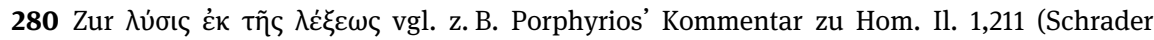

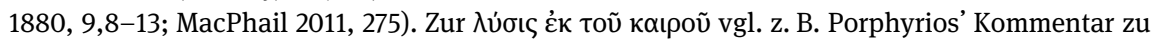
Hom. Il. 1,18 (Schrader 1880, 3,6-10). Zum Faktor kaıрó („Gelegenheit, Situation“) vgl. Theons (RhG II 115f. Spengel; Patillon und Bolognesi 1997, 70 f.) Instruktion zur Gestaltung der Figurenrede; s. Kap. 2.1.3.2.

281 Porph. Il. 1,42 (Schrader 1880, 4,1-5). Vgl. Hom. Il. 1,8-42. 
wenn Agamemnon gesund bleibt, aber seine Soldaten unter der Seuche leiden und sterben sieht. Hier bedeutet die ,(Problem-)Lösung von der Figur her“ (Por-

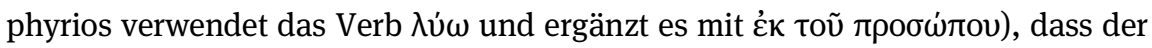
Charakter der Figur Chryses berücksichtigt wird. Die Tatsache, dass Chryses an dieser Stelle die sprechende Figur ist, oder sogar der Kontrast zwischen der Autor- und der Figurenrede ist zumindest nebensächlich.

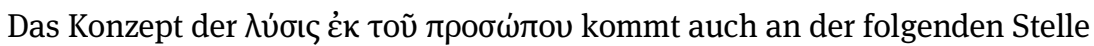
zum Vorschein, ohne dass Porphyrios über eine Figurenrede reflektiert: ${ }^{282}$

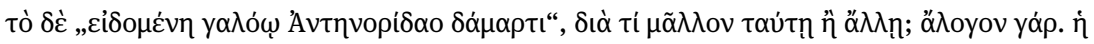

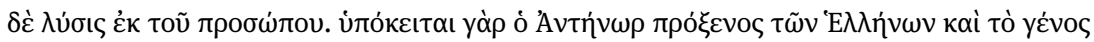

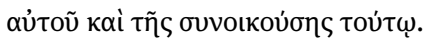

[Der Ausdruck „die ihrer Schwägerin ähnlich sah, der Frau des Antenoriden“: warum eher ihr als einer anderen? Das ist nämlich unlogisch. Die Lösung ergibt sich aber von der Figur her. Antenor war nämlich ein Freund der Griechen und ebenso die Familie von ihm und seiner Ehepartnerin.]

Porphyrios behandelt das Problem, dass im dritten Buch der Ilias die Rede davon ist, dass Iris Helena eine Botschaft überbringt, wobei sie das Aussehen der Laodike, der Frau des Helikaon, eines Sohnes des Antenor, annimmt. Er stellt sich die Frage, warum Iris gerade Laodikes Gestalt annimmt, und sieht die Antwort darin, dass sie zur Familie des Trojaners Antenor gehört, die freundschaftlich mit den Griechen verbunden war.

\subsection{Die statischen Elemente der Erzählung}

Auch wenn eine Erzählung grundsätzlich eine Darstellung von Ereignissen ist, werden in ihr zumeist auch statische Elemente geschildert. $\mathrm{Zu}$ den in der antiken Erzähltheorie diskutierten statischen Elementen gehören i.W.: Beschreibungen (allerdings handelt es sich bei der antiken Beschreibung im Unterschied zum modernen Begriff der Beschreibung nur mehr oder minder um ein statisches Element, da sich die Beschreibung nach antiker Auffassung durch das Kriterium der Anschaulichkeit von der Erzählung unterscheidet, wobei nicht nur Orte, Zeiten, Dinge und Personen, sondern auch Ereignisse anschaulich beschrieben werden können; s. Kap. 1.1.3.3); Lob und Kritik; biographische Angaben.

Über die Vermischung von dynamischen und statischen Elementen der Erzählung wird insbesondere in den antiken Progymnasmata-Handbüchern reflek-

282 Porph. Il. 3,122 (Schrader 1880, 55,3-6; MacPhail 2011, 277 f.). 
tiert. $^{283}$ (Pseudo-)Hermogenes und Priscian weisen nämlich darauf hin, dass einige Grammatiker die Beschreibung nicht als eigenes Progymnasma aufgefasst haben, da sie bereits in den vorher behandelten Übungen der Fabel (fabula) und der Erzählung (narratio) enthalten sei: ${ }^{284}$

sciendum autem, quod quidam non posuerunt descriptionem in praeexercitamentis, quasi praeoccupatam et in fabula et in narratione; in illis enim quoque describimus et loca et fluvios et personas et res; sed quoniam eam quoque quidam eloquentissimorum tradidere inter praeexercitationes, non incongruum est eos imitari.

[Man muss aber wissen, dass einige [sc. Grammatiker] die Beschreibung nicht unter die Progymnasmata aufgenommen haben, da sie sozusagen sowohl in der Fabel als auch in der Erzählung vorweggenommen sei; in diesen [sc. Übungen] beschreiben wir nämlich auch Orte, Flüsse, Personen und Dinge/Ereignisse. Aber da einige der am besten ausgewiesenen rhetorischen Fachleute auch sie [sc. die Beschreibung] innerhalb der Progymnasmata überliefert haben, ist es nicht unangebracht, es genauso wie sie zu machen.]

Die Einsicht, dass in der Erzählung auch beschreibende Elemente vorkommen, hält aber diese beiden ebenso wenig wie die anderen uns überlieferten Verfasser von Progymnasmata-Handbüchern davon ab, eine eigene Übung der Beschreibung vorzusehen.

\subsubsection{Beschreibungen}

$\mathrm{Zu}$ den Aufgaben des Geschichtsschreibers, die der Ciceronische Antonius in De oratore skizziert (s. Kap. 2.1.3.3), gehört auch die Beschreibung von Regionen.

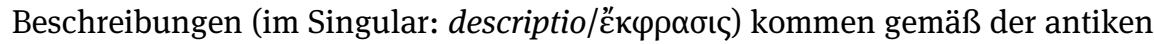
Erzähltheorie in allen erzählenden Gattungen vor, wobei in der Art und Weise, wie der Dichter auf der einen und der Historiker oder Redner auf der anderen Seite diese zu gestalten hat, ein Unterschied gesehen wurde. In diese Richtung weisen die folgenden Reflexionen: ${ }^{285}$

historia [. . .], in qua et narratur ornate et regio saepe aut pugna describitur. ${ }^{286}$

283 Schon die Tatsache, dass es sich um unterschiedliche Übungen handelt, die auf das Halten der ganzen Rede vorbereiten, zeigt die Einsicht, dass sich in der Rede dynamische und statische Elemente vermischen.

284 Priscian, Praeexercitamina Passalacqua $(1987,47)$. Vgl. die identischen Äußerungen Hermog. Progym. 10,7 Patillon (2008, 203).

285 Vgl. Leeman et al. (1985, 267) ad Cic. de orat. 2,63. Zur (Orts-)Beschreibung in Polybios' Urteil vgl. Polyb. 5,21,6f.; 29,12,4; Avenarius (1954, 147 f.).

286 Cic. orat. 66. 
[Die Geschichtsschreibung, in der durch den Einsatz von Redeschmuck erzählt wird und häufig eine Region oder ein Kampf beschrieben wird.]

interim admonere illud sat est, ut sit ea [sc. narratio] neque arida prorsus atque ieiuna [. . .] neque rursus sinuosa et arcessitis descriptionibus, in quas plerique imitatione poeticae licentiae ducuntur, lasciviat. ${ }^{287}$

[Einstweilen genügt es, darauf hinzuweisen, dass sie [sc. die Erzählung] weder gänzlich trocken und dürr noch wiederum voller Abschweifungen sein und durch hergeholte Beschreibungen ausschweifen soll, zu denen sehr viele durch Nachahmung der dichterischen Lizenz verleitet werden.]

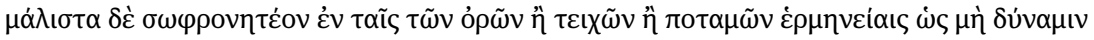
$\lambda$

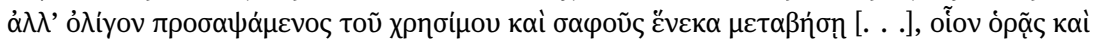

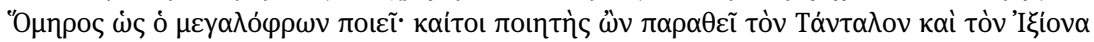

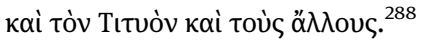

[Besonders bei den Schilderungen von Gebirgen, Mauern oder Flüssen muss man Maß halten, damit man nicht den Eindruck erweckt, wahllos seine Wortgewalt zur Schau zu stellen und seiner Eitelkeit zu dienen, wobei man die Geschichtsschreibung aus den Augen verliert. Wende sie im geringen Ausmaß an, um zur Nützlichkeit und Klarheit beizutragen, und gehe zu anderem über, wie es auch der großgesinnte Homer macht, wie du siehst. Denn obwohl er ein Dichter ist, erwähnt er nur kursorisch Tantalos, Ixion, Tityos und die übrigen.]

Die Beschreibungen bzw. Schilderungen des Historikers (und Redners) sollen also maßvoll sein und können in dieser Hinsicht im Gegensatz zum Dichter stehen, der sich dabei eine größere stilistische Freiheit erlauben darf. Lukians Äußerungen über Homer zeigen aber, dass dessen zurückhaltende Beschreibungstechnik sogar als Ziel des Historikers gelten kann. Außerdem zeigen Horaz’ Anweisungen, dass auch die Dichter eine Beschreibung nicht als Selbstzweck einflechten dürfen, sondern diese zweckmäßig und angemessen einsetzen sollen: ${ }^{289}$

inceptis gravibus plerumque et magna professis purpureus, late qui splendeat, unus et alter adsuitur pannus, cum lucus et ara Dianae et properantis aquae per amoenos ambitus agros aut flumen Rhenum aut pluvius describitur arcus; sed nunc non erat his locus.

[Sehr häufig wird hochtrabenden Anfängen, die Großes in Aussicht gestellt haben, das ein oder andere Tuch, das weithin glänzt, angenäht, wenn der Hain und der Altar der Diana

287 Quint. inst. 2,4,3.

288 Luk. hist. conscr. 57. Zu Lukian s. Kap. 2.2.2.

289 Hor. ars 14-19. 
und der Lauf des geschwinden Wassers durch die anmutigen Felder oder der Rheinstrom oder ein Regenbogen beschrieben wird; aber jetzt war dafür nicht der richtige Ort.]

Die Beschreibung muss daher sowohl vom Historiker als auch vom Dichter funktional eingesetzt werden. Der Dichter darf sich aber eine größere stilistische Freiheit erlauben, wie insbesondere Quintilian bezeugt, wobei zu berücksichtigen ist, dass Quintilian grundsätzlich in einer Trias zwischen den Stilen der (Gerichts-)Rede, der Geschichtsschreibung und der Dichtung unterscheidet, indem die stilistische Freiheit von Gattung zu Gattung zunimmt. ${ }^{290}$

\subsubsection{Lob und Kritik}

Auch die Anforderung, bei Überlegungen zu erkennen zu geben, was der Autor gutheißt, also Lob und Kritik, gehören zu den Aufgaben des Geschichtsschreibers, die der Ciceronische Antonius in De oratore skizziert (s. Kap. 2.1.3.3). Instruktionen zum Lob in der Geschichtsschreibung finden sich auch in Lukians Essay „Wie man Geschichte schreiben soll“, ${ }^{291}$ wobei diese bei Lukian nicht auf die Überlegungen beschränkt sind. Ferner sind Lob und Kritik auch in anderen erzählenden Gattungen vorgesehen, allerdings in unterschiedlicher Ausprägung, wie man daran erkennen kann, dass Lukian einerseits das panegyrische Lob als Selbstzweck von der Geschichtsschreibung abgrenzt und es der Panegyrik und der Dichtung zuweist: ${ }^{292}$

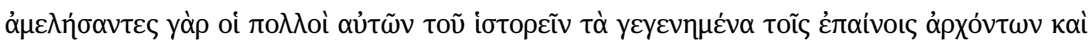

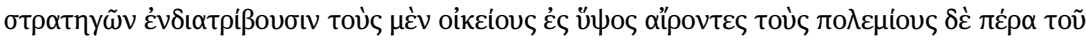

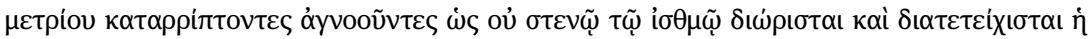

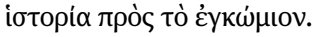

[Die meisten von ihnen versäumen es, das Geschehene zu berichten, und loben stattdessen ausgiebig Herrscher und Feldherren, wobei sie die eigenen in den Himmel heben und die feindlichen maßlos zerreißen. Sie wissen nicht, dass die Geschichtsschreibung durch einen nicht schmalen Spalt gegenüber der Lobrede abgetrennt und abgeschirmt ist.]

290 Vgl. Quint. inst. 10,1,31 und 33.

$291 \mathrm{Zu}$ Lukians Werk „Wie man Geschichte schreiben soll“ vgl. den Kommentar von Porod (2013); Avenarius (1954). Zu Lob und Kritik als Übungsformen (Progymnasmata) vgl. Quint. inst. 2,4,20; Theon RhG II 109-112 Spengel (Patillon und Bolognesi 1997, 74-78); Hermog. Progym. 7 Patillon (2008, 194-198); Aphth. Progym. 8-9 Patillon (2008, 131-140); Nikolaos RhG XI 47-58 Felten; Priscian, Praeexercitamina Passalacqua (1987, 42-44); vgl. auch die Übersicht bei Kennedy (2003, XIII).

292 Luk. hist. conscr. 7. Zum panegyrischen Lob in der Dichtung vgl. auch Luk. hist. conscr. 8. 
Andererseits verbietet Lukian das Lob in der Geschichtsschreibung nicht gänzlich, sondern toleriert bzw. empfiehlt das maßvolle Lob: ${ }^{293}$

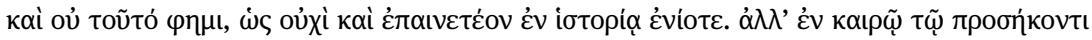

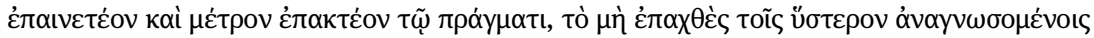

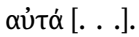

[Und ich sage nicht, dass man in der Geschichtsschreibung nicht auch mal loben darf. Aber man muss zum richtigen Zeitpunkt loben und der Sache ein Maß auferlegen, das bei den späteren Lesern keinen Anstoß erregt.]

Daher liegen die Unterschiede zwischen der Geschichtsschreibung und den dichterischen Erzählungen beim Lob im unterschiedlichen Ausmaß. Die Dichter und Panegyriker dürfen die dargestellten Figuren über alle Maßen loben und dabei auch gegen das Wahrheitspostulat verstoßen. Soweit darf der Historiker nicht gehen (zum Wahrheitspostulat in der Geschichtsschreibung s. Kap. 1.4.2.1). Von ihm wird aber erwartet, dass er Stellung zu kritischen Entscheidungen bezieht.

Eine Sonderform von Lob und/oder Kritik liegt im Nachruf vor, in dem rückblickend die Lebensleistungen eines berühmten Menschen gewürdigt werden, so dass hierin teilweise auch biographische Angaben (s. Kap. 2.2.3) gesehen werden können. Seneca d.Ä. versucht an der folgenden Stelle in Bezug auf die Historikerfragmente über Ciceros Tod, einen Begriff für dieses Phänomen zu finden, das seit langem in der Historiographie existierte, ohne dass es einen etablierten Fachbegriff hierfür gab: ${ }^{294}$

quotiens magni alicuius mors ab historicis narrata est, totiens fere consummatio totius vitae et quasi funebris laudatio redditur. hoc, semel aut iterum a Thucydide factum, item in paucissimis personis usurpatum a Sallustio, T. Livius benignus omnibus magnis viris praestitit. sequentes historici multo id effusius fecerunt. Ciceroni hoc, ut Graeco verbo

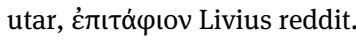

[Fast immer wenn der Tod eines großen [sc. Menschen] von Historikern erzählt worden ist, wird eine Zusammenfassung des ganzen Lebens und gewissermaßen eine Grabrede

293 Luk. hist. conscr. 9.

294 Sen. suas. 6,21. Zu Text und Kommentar vgl. Feddern (2013, v. a. 448-450), der die Bedeutung „Nachruf“ für consummatio totius vitae et quasi funebris laudatio und غ̇ंıт́́ $\varphi ı$ herausstellt. Zu Thukydides vgl. den Nachruf auf Perikles (Thuk. 2,65); zu Sallust vgl. den Nachruf auf Sulla (Sall. hist. 1 fr. 58 Maur.); zu Livius vgl. den Nachruf auf Scipio Africanus (Liv. 38,53,9-11) und auf Q. Fabius Maximus ,Cunctator (Liv. 30,26,9). Zum lobenden Charakter des Nachrufes vgl. auch Livius' Aussage, dass es des Lobredners Cicero bedürfte, um Cicero angemessen zu würdigen (Sen. suas. 6,22): si quis tamen virtutibus vitia pensaret, vir magnus ac memorabilis fuit, et in cuius laudes exsequendas Cicerone laudatore opus fuerit. [Wenn aber jemand die Fehler mit den Vorzügen gegenrechnen würde, war er ein großer und erinnerungswürdiger Mann und jemand, für dessen Lobrede ein Cicero als Lobredner nötig gewesen wäre.] 
(laudatio funebris) gehalten. Nachdem Thukydides es ein- oder zweimal gemacht hat und Sallust ebenso bei sehr wenigen Personen Gebrauch davon gemacht hat, hat Titus Livius dies gewogen allen großen Männern gewährt. Die nachfolgenden Historiker haben es viel verschwenderischer gemacht. Livius hat Cicero diese - um das griechische Wort zu ver-

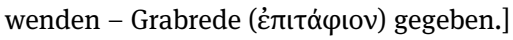

Diese Stelle zeigt, dass - zumindest in der Einschätzung des älteren Seneca in der Historiographie in einem immer stärkeren Ausmaß der Autor einen Nachruf auf einen verstorbenen berühmten Mann verfasst hat, nachdem er dessen Tod geschildert hat. Dabei muss man zwischen zwei (häufig miteinander verknüpften) Elementen unterscheiden, nämlich der Schilderung des Todes eines berühmten Mannes (exitus) als dynamischem Element und dem Nachruf als statischem Element, das Historiker immer stärker zu der vorangegangenen Schilderung hinzugefügt haben.

\subsubsection{Biographische Angaben}

$\mathrm{Zu}$ den Aufgaben des Geschichtsschreibers, die der Ciceronische Antonius in De oratore skizziert (s. Kap. 2.1.3.3), gehören auch biographische Angaben über die wichtigsten Protagonisten, da diese Informationen dazu beitragen, die Entwicklung des Geschehens verständlich zu machen. In De inventione konzipiert Cicero eine Erzählgattung, die personenzentrierte Erzählung (narratio in personis posita), in Abgrenzung zur ereigniszentrierten Erzählung (narratio in negotiis posita), wobei diese beiden Erzählgattungen nicht absolut, sondern in der Form voneinander unterschieden werden, dass in der einen Erzählgattung die Personen und in der anderen die Ereignisse im Vordergrund stehen (s. Kap. 1.4.2.2).

Die personenzentrierte Erzählung ist am besten als charakterisierende Erzählung erklärt, ${ }^{295}$ zu der Biographien und biographische Passagen gehören: ${ }^{296}$

illa autem narratio, quae versatur in personis, eiusmodi est, ut in ea simul cum rebus ipsis personarum sermones et animi perspici possint, hoc modo:

„venit ad me saepe clamitans: quid agis, Micio?

295 In der narratio in personis posita hat man eine „Erzählung in dramatischer Form“ gesehen. Hiermit ist gemeint, dass es sich um Erzählungen handelt, die in der (aus späteren Quel-

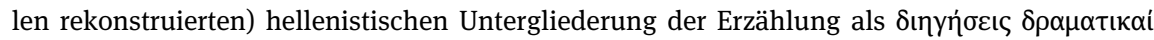
bezeichnet wurden, also Figurenreden in Opposition zu anderen Darstellungsweisen, die rein formal nach dem Platonischen Redekriterium (s. Kap. 3.2.1.1) unterschieden wurden. Für diese Ansicht vgl. Barwick (1928, 277-281); Matthes (1958, 200); Calboli (1969, 215) ad rhet. Her. 1,12 f. Für eine Diskussion vgl. Feddern (2017).

296 Cic. inv. 1,27. 
cur perdis adulescentem nobis? cur amat?

ur potat? cur tu his rebus sumptum suggeris,

vestitu nimio indulges? nimium ineptus es.

nimium ipse est durus praeter aequumque et bonum.“

hoc in genere narrationis multa debet inesse festivitas, confecta ex rerum varietate, animorum dissimilitudine, gravitate, lenitate, spe, metu, suspicione, desiderio, dissimulatione, errore, misericordia, fortunae commutatione, insperato incommodo, subita laetitia, iucundo exitu rerum. verum haec ex iis, quae postea de elocutione praecipientur, ornamenta sumentur.

[Diejenige Erzählung aber, die sich mit den Personen befasst, ist von der Art, dass in ihr zugleich mit den Sachen selbst die Gespräche und Charaktere der Menschen durchschaut werden können, z. B.:

„Er [sc. mein Bruder] kommt häufig schreiend zu mir: ,Was machst du da, Micio? Warum verdirbst du uns den jungen Mann? Warum liebt er? Warum trinkt er? Warum gibst du ihm für diese Dinge Geld, hast Nachsicht mit übertriebener Kleidung? Du bist allzu nachlässig. Er selbst [sc. mein Bruder] ist streng über Gebühr und mehr, als angemessen und gut ist.“

In dieser Art von Erzählung muss viel Redeschmuck liegen, der sich ergibt aus der Abwechslung der Dinge, der Verschiedenheit der Einstellungen, Würde, Milde, Hoffnung, Furcht, Verdacht, Sehnsucht, Verstellung, Irrtum, Mitleid, Veränderung des Schicksals, unerwartetem Vorteil, plötzlicher Freude, einem erfreulichen Ausgang von Ereignissen. Aber diese Schmuckmittel werden aus denjenigen bestritten, die später in der Lehre über die Ausformulierung genannt werden.]

Der älteste erhaltene Kommentar zur fraglichen Stelle in De inventione, derjenige des Marius Victorinus, schlägt eine plausible Deutung der personenzentrierten Erzählung und des Verhältnisses zwischen dieser und der ereigniszentrierten Erzählung vor. ${ }^{297}$ Marius Victorinus erklärt nämlich die Mischformen dadurch, dass in ereigniszentrierten Erzählungen primär Ereignisse geschildert werden, aber auch der Charakter der beteiligten Person(en) beschrieben wird, damit die Ereignisse (wir würden sagen: ihre Motivierung) verständlicher werden (wird). Als Beispiele werden namentlich Catilina und Sertorius erwähnt, womit Marius Victorinus auf Sallusts historiographische Werke anspielt, da Catilina im beinahe gleichnamigen Werk die Hauptrolle spielt, ${ }^{298}$ während Sertorius in den Fragmenten der Historiae zum Vorschein kommt. ${ }^{299}$ Analog wird in personenzentrierten

297 Vgl. Mar. Vict. rhet. 1,27 nach der Textausgabe von Riesenweber (2013, 69). Eine andere Verhältnisbestimmung zwischen der Handlung und den Protagonisten (innerhalb einer Erzählung) nimmt Aristoteles vor, indem das Ethos ein wichtiger Parameter ist, der zur Handlungswahrscheinlichkeit beiträgt; s. Kap. 1.4.1.2; 2.1.3.1. Zu Marius Victorinus vgl. auch Riesenwebers textkritischen Kommentar (Riesenweber 2015).

298 Für die Beschreibung von Catilinas Charakter vgl. Sall. Cat. 5. Man denke auch an Thukydides' Charakterisierung von Pausanias und Themistokles (Thuk. 1,128-138).

299 Vgl. Burkard (2010, XVIII). 
Erzählungen primär der Charakter der beteiligten Person(en) beschrieben, es werden aber auch diejenigen Ereignisse geschildert, für die die beteiligte Person verantwortlich ist, damit ihr Charakter deutlicher hervortritt. ${ }^{300}$

Die Deutung der narratio in personis posita als charakterisierende Erzählung wird durch das von Cicero zitierte Beispiel (die Verse 60-64 aus Terenz' Komödie Adelphoe) gestützt. ${ }^{301}$ An der Terenzstelle berichtet Micio in einem Monolog, dass sein Bruder Demea häufig zu ihm kommt und mit ihm über die richtige Form der Erziehung streitet. Dann zitiert Micio Demeas Vorwurf, dass er (Micio) mit Aeschinus allzu nachsichtig sei. Schließlich folgt hierauf Micios Replik, dass Demea in Erziehungsfragen allzu streng sei. Cicero zitiert nur den ersten Vers der Replik; bei Terenz schließen sich hieran viele Verse an, in denen Micio darlegt, dass die bessere Erziehungsmethode darin besteht, den jungen Menschen mit Zuneigung und Nachsicht zu begegnen. ${ }^{302}$ In diesem Beispiel für die personenzentrierte Erzählung stehen also das Gespräch und der Charakter des Demea im Vordergrund, den Micio erst durch ein Zitat und dann durch eine direkte Aussage charakterisiert. ${ }^{303}$

Daher reflektiert die Unterscheidung zwischen der charakterisierenden und der ereigniszentrierten Erzählung den Umstand, dass Erzählungen sowohl dynamische als auch statische (biographische) Elemente beinhalten können, aber nicht müssen.

\subsection{Die Zeit}

Mehrere systematische Unterscheidungen betreffen die Zeit der Erzählung auf der Ebene der Geschichte (zur Zeit auf der Ebene der Darstellung s. Kap. 3.1). Zum einen gehört hierher die Frage, welche Zeitstufe (Vergangenheit, Gegenwart, Zukunft) dargestellt wird (Kap. 2.3.1). Zweitens muss innerhalb der doppelten Zeitperspektive zwischen der prospektiven und der retrospektiven Betrachtung einer Ereignissequenz unterschieden werden (Kap. 2.3.2). Drittens werden in der antiken Erzähltheorie produktionsorientierte Anweisungen gegeben, dass der

300 Vgl. Calboli Montefusco (1988, 59f. und 2006, 27), die sich ebenfalls Marius Victorinus anschließt. Knapes (2003, 101) Erklärung der narratio in personis posita ist undeutlich, aber wohl ebenso zu verstehen.

301 Zur Rezeption der Adelphoe bei Cicero (und Augustinus) vgl. Schultheiß (2007).

302 Vgl. Ter. Adel. 64-77, v. a. 64-67.

303 Zur charakterisierenden Erzählung vgl. auch die vom Anonymus Seguerianus konzipier-

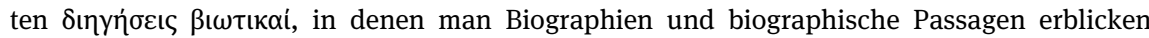
muss; vgl. Anon. Seg. 53-55 Dilts und Kennedy $(1997,18)$. 
Verfasser einer Erzählung neben anderen Elementen den Faktor Zeit berücksichtigen soll (s. Kap. 2.1.2.2 und Kap. 2.1.3.2). Und viertens gibt es rezeptionsorientierte Überlegungen, die zwischen der Zeit der Handlung, derjenigen des Autors und derjenigen des Rezipienten unterscheiden (Kap. 2.3.3). ${ }^{304}$

\subsubsection{Die Zeitstufen der erzählten Geschichte}

In der modernen Erzähltheorie wird unter der Rubrik der Stimme der Zeitpunkt des Erzählens beleuchtet, indem drei Möglichkeiten genannt werden, wie sich der Zeitpunkt des Erzählens zur erzählten Geschichte verhält: Beim späteren Erzählen berichtet der Autor bzw. Erzähler von vergangenen Ereignissen; beim gleichzeitigen Erzählen schildert er eine gegenwärtige Geschichte; und beim früheren Erzählen spielt die Handlung in der Zukunft. Hinzu kommt, dass sich die möglichen Zeitpunkte des Erzählens vervielfältigen können, wenn eingeschobene Erzählungen die Rahmenerzählung unterbrechen. ${ }^{305}$

In der antiken Erzähltheorie wird nicht der Zeitpunkt des Erzählens, sondern es werden die drei Zeitstufen der erzählten Geschichte unterschieden: Die dargestellten Ereignisse liegen in der Vergangenheit, Gegenwart oder Zukunft. Daher handelt es sich um eine Unterscheidung, die nicht zur Ebene der Darstellung (genau genommen: zum erzählenden Akt) gehört, sondern zur Ebene der Geschichte, weil danach gefragt wird, was (welche Zeit) dargestellt wird. Diese Diskrepanz hängt damit zusammen, dass der erzählende Akt ein modernes Konzept ist, das die Ebene der Darstellung weiter differenziert (s. die einleitenden Bemerkungen zu Kap. 3).

Die Einsicht, dass in Erzählungen die Vergangenheit, Gegenwart oder $\mathrm{Zu}$ kunft dargestellt wird, findet sich $\mathrm{u}$. a. in den Rhetorik-Handbüchern, in denen die drei Redegattungen (genera causarum) durch ihren unterschiedlichen Adressaten- und Zeitbezug unterschieden werden (s. Kap. 1.3): In der Gerichtsrede

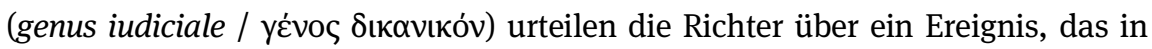
der Vergangenheit stattgefunden hat; in der politischen Rede (genus deliberati-

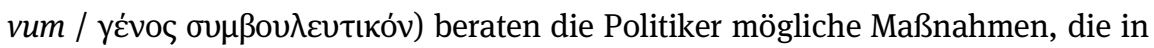
der Zukunft ergriffen werden sollen; und die Prunkrede (genus demonstrativum /

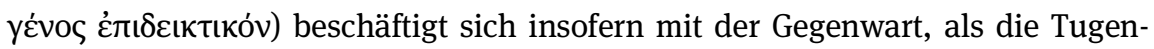
den eines Menschen gelobt und seine Fehler kritisiert werden. ${ }^{306}$

304 Zur Zeit in der antiken Erzähltheorie vgl. Grethlein (2019).

305 Vgl. Martinez und Scheffel (2016, 73-79).

306 Die Zuweisung der drei Zeitstufen zu den drei Redegattungen ist nicht absolut. So betrachtet Aristoteles zwar die Zeitstufe der Zukunft als charakteristisch für die politische Rede; 
Eine Unterscheidung der drei Zeitstufen der erzählten Geschichte findet sich aber nicht nur in den Rhetorik-Handbüchern und ist nicht beschränkt auf die Rede. Auch in Platons Dichterkritik (s. Kap. 1.4.1.1) werden im Zusammenhang mit dem Redekriterium (s. Kap. 3.2.1.1) die drei Zeitstufen der erzählten Geschichte unterschieden, und diese Differenzierung betrifft die Geschichten der Dichter und Geschichtenerzähler generell: ${ }^{307}$

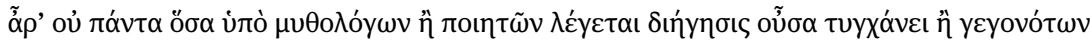

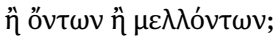

[Ist nicht nun einmal alles, was von Geschichtenerzählern oder Dichtern gesagt wird, eine Erzählung von Vergangenem, Gegenwärtigem oder Zukünftigem?]

Mit $\mu \nu \theta$ ó入oyoৎ wird ein Geschichtenerzähler gemeint sein, wie auch aus der Koordination mit den Dichtern hervorgeht, und zwar entweder ein Prosa-Schriftsteller oder (eher) in der Form, dass das Kriterium Prosa vs. Dichtung keine Rolle spielt und $\mu v \theta$ ó入oyos i. S.v. „Geschichtenerzähler“ als Oberbegriff verwendet wird. ${ }^{308}$

\subsubsection{Die doppelte Zeitperspektive}

Erzähltexte vereinigen zwei verschiedene Zeitperspektiven, die in unterschiedlicher Weise an den Autor (bzw. Erzähler), die Figuren und die Rezipienten gebunden sind: Der Autor (bzw. Erzähler) überblickt die gesamte Erzählung. Für ihn stellt die dargestellte Geschichte eine (mehr oder minder) kausal verknüpfte

vgl. Arist. rhet. 1358b13-15. An anderen Stellen wird aber deutlich, dass dies nicht ausschließlich der Fall ist und auch die Gegenwart das Bezugsfeld der politischen Rede sein kann; vgl. Arist. rhet. 1362a15f. und 1366a17f.; Beck (1970, 259f., Fn. 4).

307 Plat. rep. 392d2f. Vgl. die Koordination von Dichtern und $\mu v \theta$ oypó $\varphi$ o, womit ebenfalls Geschichtenerzähler (oder speziell Prosa-Schriftsteller) gemeint sein werden, bei Plutarch (Plut. Thes. 1,1-3).

308 Für die Koordination von Geschichtenerzählern und Dichtern vgl. Plat. leg. 941b4-8: $\mu \eta \delta$ -

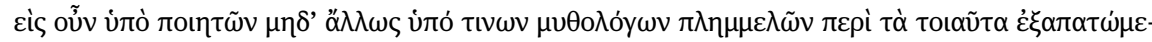

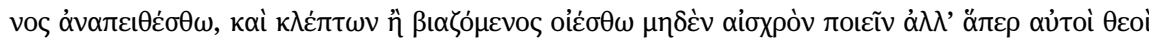
$\delta \rho \tilde{\omega} \sigma \mathrm{v}$. [Niemand soll von Dichtern oder überhaupt von irgendwelchen falsch liegenden Geschichtenerzählern über die derartigen Dinge in die Irre geführt sich überreden lassen und sich einbilden, dass er, wenn er stiehlt oder Gewalt anwendet, nichts Schimpfliches tue, sondern was die Götter selbst tun.] Der Bezug von $\pi \lambda \eta \mu \mu \varepsilon \lambda \tilde{\omega} v$ [falsch liegend] ist unsicher, da sich das

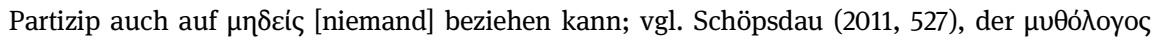
mit „Sagenerzähler“ übersetzt. Sachlich ist der Bezug auf Prosa-Schriftsteller dadurch begründet, dass einige Beobachtungen bzw. Forderungen, die sich aus der sog. Dichterkritik ergeben, für die gesamte erzählende Literatur gelten; zur sog. Dichterkritik s. Kap. 1.4.1.1. 
Ereignisabfolge dar, bei der der Anfang sinnhaft auf ein festgelegtes Ende bezogen ist und alle Ereignisse festgelegt sind. Die Rezipienten hingegen nehmen eine doppelte Zeitperspektive ein: Sie übernehmen einerseits teilweise die Perspektive des Autors (bzw. Erzählers), indem sie die Erzählung von Anfang an als abgeschlossene Handlung auffassen, die zumeist im Präteritum erzählt wird und an die sie aufgrund ihrer Leseerfahrung und der jeweiligen Gattungskonventionen sowie der hiermit verbundenen Handlungsschemata mit der Erwartungshaltung herantreten, dass der Anfang sinnhaft auf ein festgelegtes Ende bezogen ist. Andererseits ist die Erzählung für den Rezipienten offen und gegenwärtig, da er auch die Perspektive der zumeist menschlichen oder menschenähnlichen Handlungsträger einnimmt, die in Entscheidungssituationen gestellt sind und eine Zukunft zu gestalten versuchen, ohne sie mit Gewissheit steuern oder vorhersagen $\mathrm{zu}$ können. ${ }^{309}$

Über die doppelte Zeitperspektive einer Erzählung reflektiert schon Aristoteles im zweiten Teil des neunten Kapitels der Poetik in Bezug auf die Tragödie: ${ }^{310}$

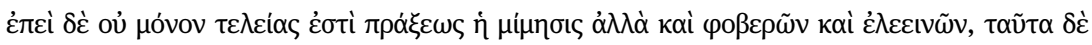

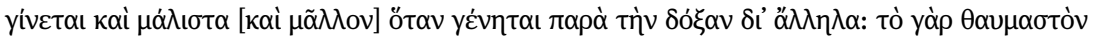

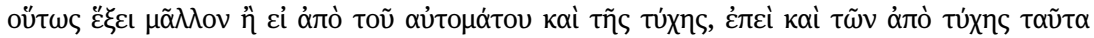

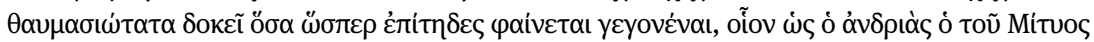

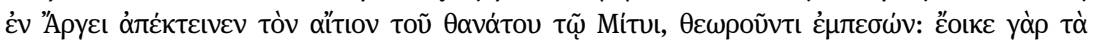

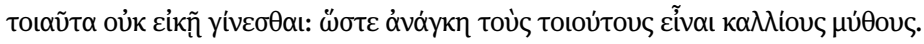

[Sie ist aber nicht nur die Nachahmung einer vollständigen Handlung, sondern auch von demjenigen, was Furcht und Mitleid erregt. Das entsteht aber am meisten, wenn es wider Erwarten auseinander entsteht. Denn das Erstaunliche wird sich auf diese Weise eher einstellen, als wenn es wie von selbst und aus Zufall geschieht, da auch von demjenigen, was aus Zufall geschieht, all das am Erstaunlichsten erscheint, was gewissermaßen absichtlich geschehen zu sein scheint - wie z. B. die Statue des Mitys in Argos denjenigen getötet hat, der Schuld am Tod des Mitys hatte, indem sie auf ihn fiel, während er sie betrachtete. Derartiges scheint nämlich nicht zufällig zu geschehen. Folglich sind die derartigen Handlungen notwendigerweise schöner.]

Die Formulierung, dass etwas wider Erwarten auseinander entsteht, erscheint paradox, da „auseinander“ ( $\delta \iota^{\prime}{ }^{\alpha} \lambda \lambda \eta \lambda \lambda$ ) bedeutet, dass die entsprechenden Ereignisse kausal motiviert sind und nicht nur zufällig nacheinander geschehen. ${ }^{311}$ Die Erklärung ergibt sich aus dem unterschiedlichen Zeitbezug, der in Aristoteles'

309 Vgl. Martinez und Scheffel (2016, 125-128).

310 Arist. Poet. 1452a1-11.

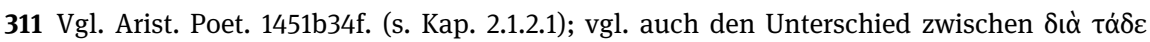
und $\mu \varepsilon \tau \alpha \grave{\alpha} \tau \alpha \dot{\delta} \delta \varepsilon$ Arist. Poet. 1452a18-21 (s. Kap. 2.1.3.1) und Schmitts (2011, 403f.) Bemerkungen zum Zufall bei Aristoteles. 
Äußerungen primär auf der Ebene der Textstruktur (und sekundär in Bezug auf den Rezipienten) beschrieben wird: Prospektiv betrachtet berechtigt der Anfang der tragischen Handlung - wenn man den aus der Gattungskonvention resultierenden groben Handlungsverlauf ausblendet - nicht zu der Annahme, dass der Hauptprotagonist ein schlimmes Unglück erleiden wird. Retrospektiv betrachtet stellt der Zuschauer - gemäß der Aristotelischen Lehre von der Handlungslogik im Laufe des Stückes und v. a. an dessen Ende fest, dass sich die Ereignisse kausal und nahezu mit Notwendigkeit auseinander ergeben (haben). ${ }^{312}$

\subsubsection{Der historische Hintergrund}

In der modernen Erzähl- und Fiktionstheorie wird dem Faktor Zeit auch insofern Rechnung getragen, als der historische Hintergrund der Erzählung aus rezeptionsorientierter Perspektive berücksichtigt wird. So stellt Schmid die Frage: „Soll man Studien in russischer und französischer Geschichte betreiben, bevor man Krieg und Frieden liest?“313 Diese Frage lässt sich wohl nicht einfach mit ,ja“ oder „nein“ beantworten, sondern in der Form, dass das Textverständnis in dem Maße gefördert wird, je mehr historisches Hintergrundwissen man aktiviert, das für die dargestellte Geschichte relevant ist.

Um eine adäquate Rezeption eines Erzähltextes aus einer anderen Epoche oder einem anderen Kulturkreis zu gewährleisten, wurde das Prinzip der allgemeinen Überzeugungen (mutual belief principle) konzipiert, das dem Realitätsprinzip eine historische Dimension verleiht. ${ }^{314}$ Denn es wäre offenkundig verfehlt, einen fiktionalen Text aus der Antike vor dem Hintergrund der realen Welt des einundzwanzigsten Jahrhunderts zu lesen. Das Prinzip der allgemeinen Überzeugungen beruht auf der Einsicht, dass die Konzeption der Alltagswirklichkeit historisch und kulturell bedingt ist. Die adäquate Rezeptionshaltung des Lesers eines fiktionalen Textes erfolgt daher in der Form, dass er den Versuch unternimmt, die Alltagswirklichkeit des Produktionszusammenhangs als Hintergrund zu nehmen.

312 Vgl. Kablitz (1996, 127).

313 Vgl. Schmid (2014, 43, Fn. 43).

314 Nach dem Realitätsprinzip (reality principle) orientiert sich die fiktive Welt so nah wie möglich an der realen Welt. Insofern kann man auch von einem principle of minimal departure sprechen, da der Autor einer fiktionalen Erzählung nur die für seine Geschichte notwendigen Abweichungen von der Realität vornimmt und der Rezipient dementsprechend reagiert. Zum Realitätsprinzip und zum Prinzip der allgemeinen Überzeugungen vgl. Lewis (1978); Zipfel (2001, 85-88); Feddern (2018, 59-62). 
Auch an einzelnen Stellen der antiken Erzähltheorie wird über den Parameter der Zeit in der Form reflektiert, dass auch der zeitliche Abstand zwischen der Gegenwart des Rezipienten, der Zeit des Autors und dem Zeitpunkt des erzählten Geschehens berücksichtigt wird. So lehrt Aristoteles im 25. Kapitel der Poetik, dass sich einige vermeintliche Probleme, die Rezipienten in dichterischen Erzählungen sehen, dadurch lösen, dass man die Zeit, zu der die Erzählung spielt, berücksichtigt (s. Kap. 2.1.5.1).

Polybios vertritt das Prinzip, dass man, wenn etwas in einer dichterischen Darstellung nicht stimmt, den Grund in Veränderungen oder in Unkenntnis oder auch im dichterischen Spielraum suchen müsse. ${ }^{315}$ Dabei ist die Kategorie der Veränderung ( $\mu \varepsilon \tau \alpha \beta$ ○一) so zu verstehen, dass es möglich ist, dass sich (geographische) Begebenheiten im Laufe der Zeit verändert haben und zu Homers bzw. Odysseus' Zeiten anders beschaffen waren als zur eigenen Zeit. ${ }^{316}$ In diesem Zusammenhang wird leider nicht deutlich, ob die Distanz zwischen der Gegenwart (Polybios hat sein Geschichtswerk in der zweiten Hälfte des zweiten Jahrhunderts v.Chr. verfasst) und Homers Zeit oder dem Zeitpunkt des erzählten Geschehens (die sich an den Trojanischen Krieg anschließende Irrfahrt des Odysseus: um 1200 v.Chr.) gemeint ist.

Der spätantike Vergil-Kommentator Servius (s. Kap. 3.1.1) differenziert an einer Stelle seines Kommentars zur Aeneis zwischen der Zeit des Autors (Ende des ersten Jahrhunderts v.Chr. und somit fast 500 Jahre vor Entstehung von Servius' Kommentar) und derjenigen der Erzählung (wie Odysseus' haben auch Aeneas' Irrfahrten nach antiker Vorstellung um 1200 v.Chr. stattgefunden). Dabei wird deutlich, dass der Rezipient grundsätzlich selbstverständlich davon ausgehen soll, dass die dargestellte Zeit, wenn die (vielleicht sogar weit zurückliegende) Vergangenheit geschildert wird, eine andere Zeit als diejenige des Autors ist. Servius benutzt für diese Unterscheidung die Ausdrücke sua [sc. Vergilii] tempora [seine [sc. Vergils] Zeiten] in Bezug auf die Zeit des Autors und tempora operis [die Zeiten des Werkes] in Bezug auf die erzählte Zeit. ${ }^{317}$ Zugleich - und darauf liegt der Schwerpunkt von Servius' Erklärung - zeigt sich, dass es Interferenzen geben kann, die der Kommentator in diesem Fall deswegen kritisiert, weil die sprechende Figur (Aeneas) im Zusammenhang mit einer topographischen Angabe das Wissen des Autors benutzt und somit einen Anachronismus verwendet, der nicht realistisch begründet werden kann (s. Kap. 3.1.2).

315 Vgl. Polyb. 34,4,1 = Strabo 1,2,17; s. Kap. 1.4.1.3.

316 Vgl. Polyb. 4,39,7-42,8; Strabo 1,2,30.

317 Vgl. Serv. Aen. 3,703; s. Kap. 3.1.2. 